OPEN ACCESS

Edited by:

Daphne Haas-Kogan,

Brigham and Women's Hospital and Harvard Medical School,

United States

Reviewed by:

Robert Dess,

University of Michigan,

United States

Eric Chi-ching Ko,

University of Massachusetts

Medical School,

United States

*Correspondence:

Sophia C. Kamran

skamran@mgh.harvard.edu

Specialty section:

This article was submitted to

Radiation Oncology,

a section of the journal

Frontiers in Oncology

Received: 02 March 2021

Accepted: 09 April 2021

Published: 07 May 2021

Citation:

Kamran SC and Efstathiou JA (2021)

Current State of Personalized

Genitourinary Cancer Radiotherapy in

the Era of Precision Medicine.

Front. Oncol. 11:675311.

doi: 10.3389/fonc.2021.675311

\section{Current State of Personalized Genitourinary Cancer Radiotherapy in the Era of Precision Medicine}

\author{
Sophia C. Kamran ${ }^{*}$ and Jason A. Efstathiou \\ Department of Radiation Oncology, Massachusetts General Hospital, Harvard Medical School, Boston, MA, United States
}

Radiation therapy plays a crucial role for the management of genitourinary malignancies, with technological advancements that have led to improvements in outcomes and decrease in treatment toxicities. However, better risk-stratification and identification of patients for appropriate treatments is necessary. Recent advancements in imaging and novel genomic techniques can provide additional individualized tumor and patient information to further inform and guide treatment decisions for genitourinary cancer patients. In addition, the development and use of targeted molecular therapies based on tumor biology can result in individualized treatment recommendations. In this review, we discuss the advances in precision oncology techniques along with current applications for personalized genitourinary cancer management. We also highlight the opportunities and challenges when applying precision medicine principles to the field of radiation oncology. The identification, development and validation of biomarkers has the potential to personalize radiation therapy for genitourinary malignancies so that we may improve treatment outcomes, decrease radiation-specific toxicities, and lead to better long-term quality of life for GU cancer survivors.

\footnotetext{
Keywords: genitourinary cancer (GU cancer), personalized radiation oncology, precision oncology, prostate cancer, testicular cancer, bladder cancer, renal cell carcinoma, precision medicine
}

\section{INTRODUCTION}

Radiation therapy is instrumental in the management of many genitourinary malignancies. Technological advances in imaging, treatment planning, and treatment delivery have allowed physicians to deliver higher radiation dose to tumor or tumor bed while minimizing dose to surrounding normal tissue. Other advances in screening and other treatment options have translated to improvements in clinical outcomes for patients with genitourinary malignancies. Yet, the optimal management for malignancies on an individualized level is not well understood. There is an urgent need to incorporate more biomarkers to personalize radiation therapy in the era of precision oncology. Here, we review the progress in the identification, development, and validation of biomarkers for genitourinary malignancies to guide treatment recommendations, as well as highlight challenges and opportunities for further investigations in personalized radiation medicine. 


\section{PROSTATE CANCER}

Prostate cancer screening, risk stratification, and treatment have advanced dramatically in the past decades. Despite this, the optimal combination of treatments for an individual is not clear nor personalized at this time. The ideal management for an individual with prostate cancer is a complicated decision process, with more than one approach often available. It is therefore imperative to determine which patients are more likely to benefit from a treatment over another, both in terms of cancer control and quality of life, in keeping with precision medicine principles. In addition, it is critical to improve diagnosis and risk stratification with respect to detecting both clinically significant and biologically aggressive disease. Below, we briefly review the current state of various innovative predictive/prognostic tools from detection through risk stratification, as well as advances in radiation delivery to further target the prostate tumor biology.

\section{Detection and Screening}

Prostate cancer detection has been aided by the use of magnetic resonance imaging (MRI). Early use in the 1990s allowed clinicians to evaluate for high-risk features such as extracapsular extension and seminal vesicle invasion $(1,2)$. Technology evolved and the inclusion of multiple parameters to evaluate the prostate, also known as the multiparametric MRI (mpMRI), has allowed for accurate localization of suspected prostate cancer lesions (3-6). At this time, tissue diagnosis with biopsy remains the gold standard, however mpMRI is a robust supplement in the diagnosis of prostate cancer. In addition, mpMRI has been increasingly incorporated into prostate biopsies by serving as a guide for "targeted" lesions that are not a part of the standard systematic biopsies. This can be accomplished using either a "cognitive" fusion biopsy or an MRI-transrectal ultrasound fusion biopsy. Both have demonstrated improved detection of clinically significant disease and overall disease burden in multiple studies (7-11). A recent phase 3 randomized trial determined that an MRI followed by selected targeted biopsy was noninferior to a standard 12-core transrectal ultrasound biopsy in detecting Gleason $3+4$ (Grade Group 2) disease or higher (12). mpMRI will continue to play a large role in the detection of prostate cancer as well as in active surveillance.

There are multiple biomarkers that exist designed to be used to aid in the diagnosis of prostate cancer before a positive prostate biopsy (Table 1). Serum biomarkers notably include: 1) the Prostate Health Index (PHI) which combines total prostate-specific antigen (PSA), free non-protein bound PSA (fPSA), and an isoform of fPSA known as p2PSA (13); and 2) the 4Kscore, which incorporates serum biomarkers including total PSA, fPSA, intact PSA, and human kallikrein 2, as well as clinical variables to predict risk of high-grade PCa on the biopsy (14). Notable urinary biomarkers include prostate cancer antigen 3 (PCA3), which is a noncoding messenger RNA (mRNA) overexpressed in prostate cancer tissue and detectable in urine after a digital rectal examination (DRE) (15). The TMPRSS2ERG genomic rearrangement can be detected in post-DRE urine samples with a specificity of $93 \%$ and a positive predictive value of $94 \%$ for prostate cancer diagnosis (16). TMPRSS2 is an androgen-regulated gene. ERG is a transcription factor that is overexpressed in $\sim 50 \%$ of primary prostate tumors (17). TMPRSS2-ERG fusions are described in $30-50 \%$ of new prostate cancer diagnoses (18). There are multiple other biomarkers as per Table 1 that can aid in the diagnosis of prostate cancer and have been shown to outperform PSA as a diagnostic tool, however their use in clinical practice is variable due to their limitations. There is a need to validate and compare these biomarkers against each other in a prospective manner before incorporating into routine clinical practice.

Molecular imaging, most notably, has exploded on the scene in the past few years with the development of several radiolabels specific for prostate cancer. Historically, the role of PET/CT was limited for prostate cancer diagnosis/staging. Multiple PET imaging tracers are being evaluated, with the top three most explored/promising summarized in Table $2 .{ }^{11} \mathrm{C}$-choline is a radiotracer that was previously explored for prostate cancer diagnosis, however its sensitivity and specificity values ranged from $72-87 \%$ and $62-84 \%$ respectively. In addition, choline-avid PET images could not reliably distinguish between benign and malignant lesions (19). Since that time, the PET compound ${ }^{18} \mathrm{~F}$ fluciclovine demonstrated promise for prostate cancer detection, particularly in the setting of biochemically recurrent prostate

TABLE 1 | Biomarkers for prostate cancer screening.

\begin{tabular}{|c|c|c|}
\hline Test & Biomarker & Positive \\
\hline $4 \mathrm{~K}$ & Total PSA, fPSA, intact PSA, human kallikrein 2 as well as clinical variables (age, DRE, and prior biopsy results) & $\geq 9 \%$ \\
\hline \multirow{2}{*}{ Prostate Health Index } & Formula: & \\
\hline & $(2 \mathrm{pPSA} / \mathrm{fPSA}) \times \sqrt{ } \mathrm{PSA}$ & \\
\hline \multicolumn{3}{|l|}{ Urine- post DRE } \\
\hline PCA3 & Concentration of PCA3 mRNA relative to PSA mRNA & $\geq 35$ \\
\hline \multirow{2}{*}{ SelectMDX } & RNA levels of $D L X 1$ and $H O X C 6$ & $\geq 2.8 \mathrm{RS}$ \\
\hline & Also includes total PSA, PSA density, DRE, age, family history & \\
\hline ExoDx & RNA content in extracellular vesicles, measuring RNA and calculating as sum of normalized RCA and RNA ERG & $\geq 15,6$ \\
\hline
\end{tabular}

$D R E$, digital rectal examination. 
TABLE 2 | Summary of top PET imaging tracers for prostate cancer.

\begin{tabular}{lll}
\hline PET tracer & Production method & Half-life \\
\hline Carbon $11\left({ }^{11} \mathrm{C}\right)$ choline & Cyclotron (onsite) & 20.3 min \\
Gallium $68\left({ }^{(8)} \mathrm{Ga}\right)$ PSMA & Generator & 67.7 min \\
Fluorine $18\left({ }^{18} \mathrm{~F}\right)$ fluciclovine & Cyclotron (regional) & $109.8 \mathrm{~min}$ \\
\hline
\end{tabular}

cancer (20). Generally, the sensitivity improves with a higher PSA relapse level. Due to its improved technique to detect prostate cancer lesions at lower PSAs in the recurrent setting compared to conventional imaging, this scan is FDA-approved for use in the post-treatment biochemically recurrent clinical setting. More recently, studies using targeted radiolabeling of the prostatespecific membrane antigen (PSMA) for PET/CT demonstrate promising data $(21,22)$. PSMA is a transmembrane protein that is overexpressed on prostate cancer tumor tissue; thus this can be targeted with a radioligand and lead to enhanced prostate cancer uptake and detection. Gallium 68 PSMA-11 has recently received FDA approval for use in the United States for PET imaging of PSMA positive lesions in patients with suspected prostate cancer metastasis as well as patients with suspected prostate cancer recurrence based on elevated PSA levels. Broad distribution of Gallium 68 PSMA-11 is being worked on. The proPSMA prospective trial demonstrated the superiority of PSMA PETCT ( $n=150$ men) compared to conventional imaging $(n=152$ men) for accuracy of identifying pelvic nodal or distantmetastatic disease, with a $27 \%$ absolute greater area under the curve (AUC) for accuracy over conventional imaging (92\% [8895] vs 65\% [60-69] (23). PSMA PET imaging appears to be better than fluciclovine PET at lower PSA levels. A single institutional comparison between PSMA PET and fluciclovine PET in prostate cancer patients with biochemical recurrence after radical prostatectomy (PSA $<2.0 \mathrm{ng} / \mathrm{mL}$ ) found that, in 50 enrolled patients, detection rates were lower with fluciclovine
PET (13 of 50, 26\%) versus PSMA PET (28 of 50, 56\%), with an odds ratio of 4.8 at the patient level (95\% CI 1.6-19.2, $\mathrm{p}=0.0026)(24)$.

However, not all metastatic disease, particularly castrateresistant metastatic disease, expresses PSMA. There are many ongoing trials further defining the role of Gallium 68 PSMA-11 PET in both the biochemically recurrent and diagnostic setting, particularly for advanced disease (25).

\section{Risk Stratification}

It has become increasingly evident that using clinicopathologic characteristics alone to stratify patients into various risk categories to guide treatment decisions may be insufficient, as we learn more about heterogenous outcomes in risk groups. There are newer clinical staging/risk-stratification systems that demonstrate promise. These include the STAR-CAP (26) as well as the CAPRA score (27). However, there remains a need to identify and validate markers intrinsic to tumor biology to further stratify patients into risk groups. To that end, there are currently four commercially available gene panels that can be used for localized prostate cancer (Table 3). These can be used to further risk-stratify patients to guide personalized treatment decisions.

Prolaris (Myriad Genetics, Salt Lake City, UT) is a gene expression panel consisting of 46 genes (15 housekeeper genes, 31 cell cycle progression genes) which results in a cell cycle progression (CCP) score. It is designed for use on biopsy,

TABLE 3 | Molecular tests for Prostate Cancer Risk Stratification.

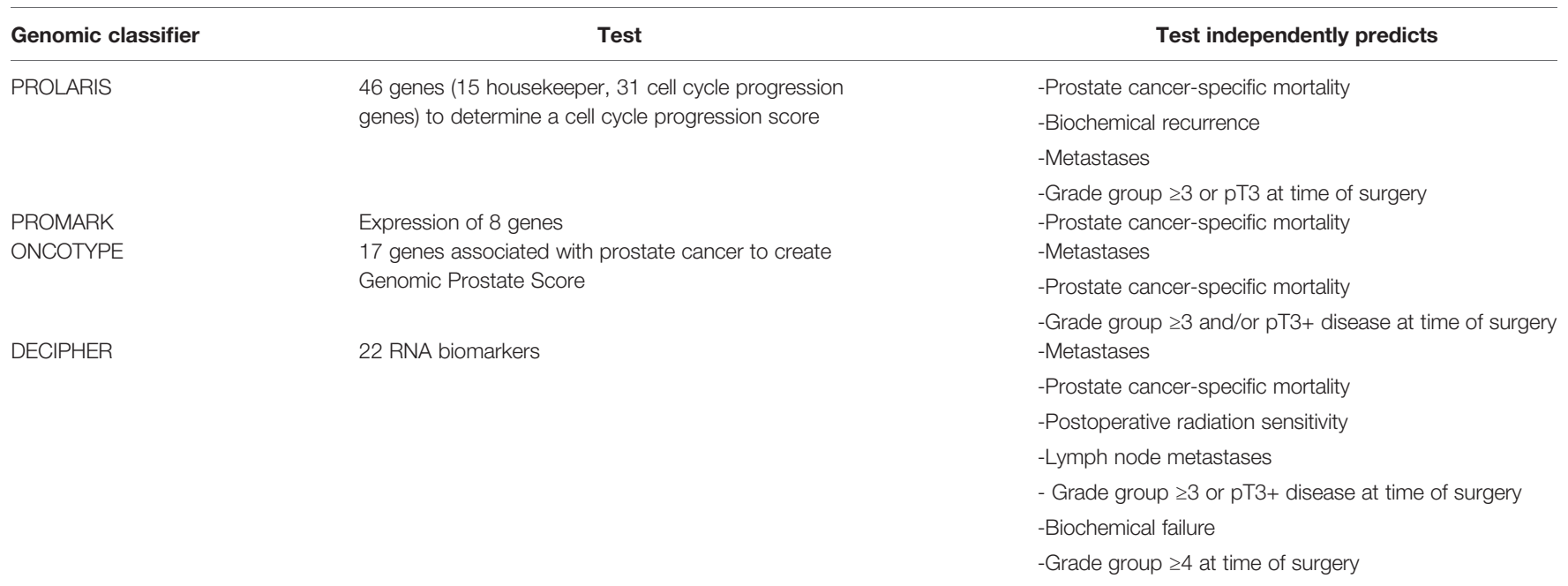


transurethral resection of the prostate (TURP) specimens, as well as radical prostatectomy specimens. There are a few studies that have evaluated the utility of this biomarker for clinical decisionmaking. Cuzick et al. used Prolaris on biopsy specimens and determined that the CCP score was the strongest independent predictor of death (28); separately the same group evaluated Prolaris in both prostatectomy and TURP specimens, demonstrating its strong performance as a prognostic factor for biochemical recurrence and time to death, respectively (29). Cooperberg et al. found that the CCP score was able to surpass the performance of a standard postoperative risk assessment score and had improved accuracy of risk stratification for outcomes for men with localized prostate cancer (30). Freedland et al. validated the Prolaris CCP score in the context of men receiving external beam radiotherapy, demonstrating its superior performance to predict recurrence and was associated with prostate cancer-specific mortality (31). Finally, a critical assessment of Prolaris by NICE determined that the use of Prolaris changed clinicians' treatment decisions in at least $47 \%$ of cases (32).

The Promark assay (Metamark Genetics Inc, Waltham, MA) uses the expression of eight different genes. This assay was validated using intact tissue biopsies and aids in classification for non-favorable pathology, providing independent prognostic data for stratifying patients (33).

A separate assay consisting of 17 genes was developed called Oncotype DX Genomic Prostate Score (Genomic Health, Redwood City, CA). The expression of these genes is incorporated into an algorithm to create a Genomic Prostate Score (GPS). The score was demonstrated to improve prediction of presence of adverse pathology $(34,35)$. Interestingly the first prospective study evaluating GPS after initial active surveillance found that there was no association of GPS with adverse pathology in those who underwent radical prostatectomy. There was also no association with upgrading in the surveillance biopsy (36).

The last assay to mention is the Decipher genome classifier (GenomeDx Biosciences, Vancouver, BC, Canada). This assay is based on the analysis of the expression of 22 genes. Decipher has been validated in multiple studies (37-41). A separate study found that in men who underwent radical prostatectomy followed by radiation, Decipher predicted both metastasis and biochemical recurrence (38). A meta-analysis published in 2017 confirmed the prognostic value of the Decipher score, independent from clinicopathologic variables. The metaanalysis included data from five studies in men who underwent radical prostatectomy. A low Decipher score was found to be associated with long-term disease control after surgery, while a higher score was found to be associated with a worse prognosis (41). There are multiple additional studies confirming the utility of Decipher in the post-operative setting, thus this is the assay with the strongest evidence to date. In addition, the Decipher test has been used in the intact setting. In a retrospective multicenter cohort study of 266 with very low, low, and favorable-intermediate risk men, it was found that the Decipher score was an independent predictor of adverse pathology, thus it is an aid to appropriately identify good candidates for active surveillance (42). In a cohort of men with intermediate-risk prostate cancer treated with radiation therapy alone, the Decipher score accurately predicted disease recurrence in these individuals at 5 years (area under the curve $0.78,95 \% \mathrm{CI}$ 0.59-0.91) (43). Decipher has been validated as part of a clinicalgenomic risk group classification for localized prostate cancer to improve risk stratification, finding that $67 \%$ of patients would be reclassified from the standard NCCN risk-system by the new system (44). In an ancillary study of the NRG/RTOG 9601 trial, Decipher was validated and independently associated with distant metastases (hazard ratio [HR] 1.17, 95\% CI 1.05-1.32, $\mathrm{p}=0.006$ ), prostate cancer-specific mortality (HR 1.39, 95\% CI $1.20-1.63, \mathrm{p}<0.001$ ), and overall survival (HR 1.17, 95\%CI 1.06$1.29, \mathrm{p}=0.002$ ), after adjusting for age, race/ethnicity, Gleason score, T stage, margin status, entry PSA, and treatment arm (45). Based on this data, several trials are incorporating this risk classifier for stratification to either intensification/deintensification treatment based on either high or low genomic risk, respectively (NRG-GU009, NCT0451371).

For advanced prostate cancer, studies have found that there are multiple mutations present in genes involved in the DNA repair pathways (DDR genes), particularly in patients with metastatic castration-resistant prostate cancer (mCRPC) (4650). These mutations have been identified as a biomarker of response to poly ADP ribose polymerase (PARP) inhibitors and platinum chemotherapy. The PROfound trial was a randomized phase 3 trial evaluating PARP inhibitor olaparib in men with mCRPC with disease progression (51). Men had to have an alteration in prespecified genes with a direct or indirect role in homologous recombination repair and were divided into cohort A (at least one alteration in BRCA1, BRCA2, or ATM, n=245 patients) and cohort $B$ (alterations in any of 12 other prespecified genes, $n=142$ patients). Imaging-based progression-free survival was longer in the olaparib group compared to control in cohort A (7.4 months versus 3.6 months, HR 0.35 , 95\% CI 0.25-0.47, $\mathrm{p}<0.001)$, yet this was less pronounced in cohort B. A significant benefit was found for olaparib in the overall population (cohorts $\mathrm{A}$ and $\mathrm{B}$ combined). Based on the promising early data (51-58), there are now multiple clinical trials ongoing to evaluate the utility of combining PARP inhibitors and platinum chemotherapy in prostate cancer patients with DDR mutations.

Separately, there have been multiple mutations associated with androgen receptor signaling in aggressive prostate cancer. A study of mCRPC patients with AR amplification who received first-line docetaxel resulted in a lower risk of death for patients with AR amplification, compared to those who received androgen receptor targeting agents (59). Similarly, in men with AR splice variant 7 (AR-S7), studies have found better outcomes with taxane treatment (60-63).

In men with $\mathrm{mCRPC}$, loss of PTEN is common, leading to the overexpression of the PI3K/AKT pathway (47). This has been shown to lead to increased AR signaling and worse overall clinical outcomes (64), thus trials are underway to combine AR-targeted and PI3K/AKT inhibitors in these populations with PTEN loss. 
A separate area of great promise for precision medicine and precision 'omics includes liquid biopsy techniques. This noninvasive technology can allow for biomarker discovery at multiple timepoints without need to rely on biopsies or other means to obtain tissue. Specifically, circulating tumor cells (CTCs), circulating tumor/cell-free DNA (ctDNA, cfDNA) provide snapshots of tumor cells and tumor-derived nucleic acids, respectively. These assays have demonstrated predictive and prognostic promise in metastatic prostate cancer (65) and early data in the localized setting is encouraging $(66,67)$.

\section{Advances in Radiotherapy Techniques, Treatment Delivery}

Major advances in radiotherapy technique and delivery have led to the ability to target the prostate gland accurately, while largely avoiding normal tissues and sparing toxicity. This has allowed for dose escalation and improved treatment outcomes. Our improved understanding of the radiobiology behind prostate cancer has led to our current efforts and advances in techniques, while eventual integration with genomic tests/molecular understanding of a prostate tumor on an individual level can allow physicians to further personalize radiation therapy with these new techniques.

Innovations in imaging and other technologies have greatly contributed to our ability to "dose-escalate" prostate radiation treatment. For example, the use of a perirectal hydrogel spacer has been shown to be associated with lower dose to the rectum as well as decreased rectal toxicity $(68,69)$. A multicenter randomized controlled trial demonstrated a reduction in late (defined as 3-15 month) rectal toxicity severity in the spacer group, with $2.0 \%$ and $7.0 \%$ late rectal toxicity incidence in the spacer and control groups, respectively $(p=0.04)(68)$. This is particularly beneficial for prostate cancer, as multiple hypotheses exist relating to the intrinsic radiobiology of prostate cancer. Emerging evidence suggests that such biology leads to greater sensitivity to increased fraction size (70). Other data suggest that prostate cancer harbors a lower $\alpha / \beta$ (a metric characterizing tissue/tumor sensitivity to radiation dose per treatment) compared to the surrounding normal tissues. This indicates that hypofractionated radiation (delivery of a higher dose to the prostate gland per treatment, for fewer total treatments) may improve cancer control. Thus, there has been great interest in moderate hypofractionation (generally accepted as 2.4-3.4 Gy per fraction $(\mathrm{fx})$ ) as well as ultrahypofractionation (generally accepted as $>4-5 \mathrm{~Gy} / \mathrm{fx})(71,72)$. Modern noninferiority trials have demonstrated excellent overall outcomes in comparison to standard fractionation (Table 4) (73-76). One superiority randomized trial comparing 75.6 Gy in 1.8 Gy/fx to $72 \mathrm{~Gy}$ in $2.4 \mathrm{~Gy} / \mathrm{fx}$ also demonstrated improved cancer control with moderate hypofractionation (77). This approach may be preferred for men with localized prostate cancer given the improved resource utilization and convenience. Ultrahypofractionated is an extreme form of hypofractionation, and there are several ongoing studies exploring its utility for localized prostate cancer. The HYPO-RT-PC trial demonstrated worse acute urinary toxicity with ultrahypofractionation (78). However, in the recently published PACE-B trial, ultrahypofractionation was not found to increase acute genitourinary or gastrointestinal toxicity (79). The ongoing RTOG 0938 trial is a phase II randomized trial evaluating 2 ultrahypofractionation regimens, $36.25 \mathrm{~Gy}$ in 5 nonconsecutive fractions or $51.6 \mathrm{~Gy}$ in 12 daily fractions; patient-reported outcome data did not demonstrate any significant difference between the two treatment schedules (80).

A separate method of "dose escalation" involves boosting visible tumor within the prostate that is visualized via multiparametric MRI with external beam radiation therapy. A recent phase III randomized controlled trial (FLAME) evaluated the utility of a focal lesion microboost in patients with intermediate- and high-risk prostate cancer (81). This demonstrated improved biochemical disease-free survival in the men who received the focal boost compared to the standard arm (HR 0.45, 95\% CI 0.28-0.71, p<0.001), and there was no impact on toxicity or quality of life. With five years of follow-up, there was no difference in prostate cancer-specific survival nor overall survival for now, but this might become significant with longer follow-up.

Proton beam technology has the physical advantage of depositing energy in the tissue at the end-of-range, thus potentially sparing critical normal tissues such as the rectum and bladder in prostate cancer patients (82). Studies to date have not demonstrated an improvement in toxicity rates or clear benefit for protons. For example, a recent multi-institutional analysis of 1850 early-stage prostate cancer patients treated with either moderately hypofractionated photon or proton therapy on a registry demonstrated low rates of toxicity and no difference in late gastrointestinal or genitourinary toxicity (83). Yet, there are several ongoing trials evaluating protons versus photons for localized prostate cancer that will help to guide our understanding of the potential benefit for protons in this clinical space. A large ongoing randomized phase III trial of proton therapy versus intensity-modulated radiation therapy for low- to intermediate-risk prostate cancer called Prostate Advanced Radiation Technologies Investigating Quality of Life, or PARTIQoL (NCT01617161), as well as large prospective observational cohorts such as a Prospective Comparative Study of Outcomes with Proton and Photon Radiation in Prostate Cancer (COMPPARE, NCT03561220) and the Japanese multiinstitutional prospective registry (UMIN000025453), will help to inform the debate between protons versus photons for localized prostate cancer.

Novel imaging techniques surrounding the identification and detection of prostate cancer as discussed above are changing how to treat this disease with radiation therapy, particularly in the post-operative setting. The role of PET/CT imaging was previously limited, however the introduction of novel imaging tracers including ${ }^{18}$ F-fluciclovine PET (Figure 1) and prostatespecific membrane antigen (PSMA) targeted agents has the potential to change clinical practice. Studies suggest that these novel radiotracers can modify radiation treatment intensification (84) as well as lead to an early improvement in failure rates (85). The LOCATE trial demonstrated increased detection of 1 or 
TABLE 4 | Moderate hypofractionation trials for prostate cancer.

\begin{tabular}{|c|c|c|c|c|c|c|c|c|}
\hline Trial & Type & Year & $\mathbf{N}$ & Trial arms & $\begin{array}{l}\text { Median } \\
\text { FU }\end{array}$ & Primary endpoint & Findings & Toxicities \\
\hline $\begin{array}{l}\text { PROFIT } \\
(73)\end{array}$ & Noninferiority & 2017 & 1206 & $\begin{array}{l}78 \mathrm{~Gy} / 39 \mathrm{Fx} \\
\text { vs } \\
60 \mathrm{~Gy} / 20 \mathrm{Fx}\end{array}$ & $6.0 \mathrm{y}$ & Disease-free survival & HR (95\% Cl): 0.96 (0.74-1.25) & $\begin{array}{l}\text { No significant difference in } \\
\text { late toxicity }\end{array}$ \\
\hline $\begin{array}{l}\text { HYPRO } \\
(74)\end{array}$ & Noninferiority & 2016 & 804 & $\begin{array}{l}78 \mathrm{~Gy} / 39 \mathrm{Fx} \\
\text { vs } \\
64.6 \mathrm{~Gy} / 19 \mathrm{Fx}\end{array}$ & $5.0 y$ & Relapse-free survival & HR (95\% Cl): 0.86 (0.63-1.16) & $\begin{array}{l}\text { Higher grade } 2+\text { acute Gl } \\
\text { toxicity with hypoFx; Higher } \\
\text { grade } 2+\text { late GU toxicity with } \\
\text { hypoFx }\end{array}$ \\
\hline $\begin{array}{l}\mathrm{CHHiP} \\
(75)\end{array}$ & Noninferiority & 2016 & 3163 & $\begin{array}{c}74 \text { Gy/37 Fx } \\
\text { vs } \\
60 \text { Gy/20 Fx } \\
\text { vs } \\
57 \text { Gy/19 Fx } \\
+ \\
\text { 3-6 mo ADT }\end{array}$ & $5.2 \mathrm{y}$ & Time to biochemical failure & $\begin{array}{l}\text { HR }(95 \% \mathrm{Cl}): 0.84(0.68-1.03) \\
57 \text { Gy/19 Fx inferior to } \\
74 \text { Gy/37 x }\end{array}$ & $\begin{array}{l}\text { No significant differences but } \\
\text { trend toward increased late } \\
\text { grade } 2+\text { GU toxicity }\end{array}$ \\
\hline $\begin{array}{l}\text { RTOG } \\
0415 \\
(76)\end{array}$ & Noninferiority & 2016 & 1092 & $\begin{array}{l}\text { 73.8Gy/41 Fx } \\
\text { vs } \\
70 \mathrm{~Gy} / 28 \mathrm{Fx}\end{array}$ & 5.8 y & Disease-free survival & HR (95\% Cl): 0.85 (0.64-1.14) & $\begin{array}{l}\text { Increased GI/GU late grade 2+ } \\
\text { with hypofx }\end{array}$ \\
\hline $\begin{array}{l}\text { Hoffman } \\
\text { et al. } \\
(77)\end{array}$ & Superiority & 2018 & 206 & $\begin{array}{l}75.6 \mathrm{~Gy} / 42 \mathrm{Fx} \\
\text { vs } \\
72 \mathrm{~Gy} / 30 \mathrm{Fx}\end{array}$ & 8.5 y & PSA failure & $\begin{array}{l}\text { 8-y failure rate } 10.7 \% \text { (95\% Cl: } \\
5.8 \%-19.1 \%) \text { for } 72 \text { Gy vs } \\
15.4 \%(95 \% \mathrm{Cl}: 9.1 \%-25.4 \%) \\
\text { for } 75.6 \mathrm{~Gy}, \mathrm{P}=0.036\end{array}$ & $\begin{array}{l}\text { Nonsignificant increase in late } \\
\text { grade } 2+\text { Gl toxicity with } \\
\text { hypoFx }\end{array}$ \\
\hline
\end{tabular}

more recurrences using ${ }^{18} \mathrm{~F}$-fluciclovine PET/CT in men with biochemical recurrence (122 of 213 patients, 57\%), and 59\% of patients had a change in management after the scan (86). Similarly, the FALCON trial demonstrated that the use of ${ }^{18} \mathrm{~F}$ fluciclovine PET/CT in 104 men with biochemical recurrence resulted in $64 \%$ of patients with a change in treatment management (87). Multiple prospective trials are underway in various prostate cancer settings (diagnostic, localized, postoperative, recurrent, metastatic) to further standardize and validate its use in various clinical settings.
As precision oncology continues to evolve for the management of prostate cancer with improved biomarkers and improved detection of disease, the role of radiation therapy is also evolving, particularly with regards to the definitive management of oligometastatic disease. Oligometastatic disease refers to a stage where metastatic disease is still limited, and aggressive therapy directed at involved lesions may improve outcomes. The definition of oligometastatic prostate cancer varies, as the CHAARTED study defined oligometastatic disease as $\leq 3$ metastases, and no visceral metastases (88), yet other studies

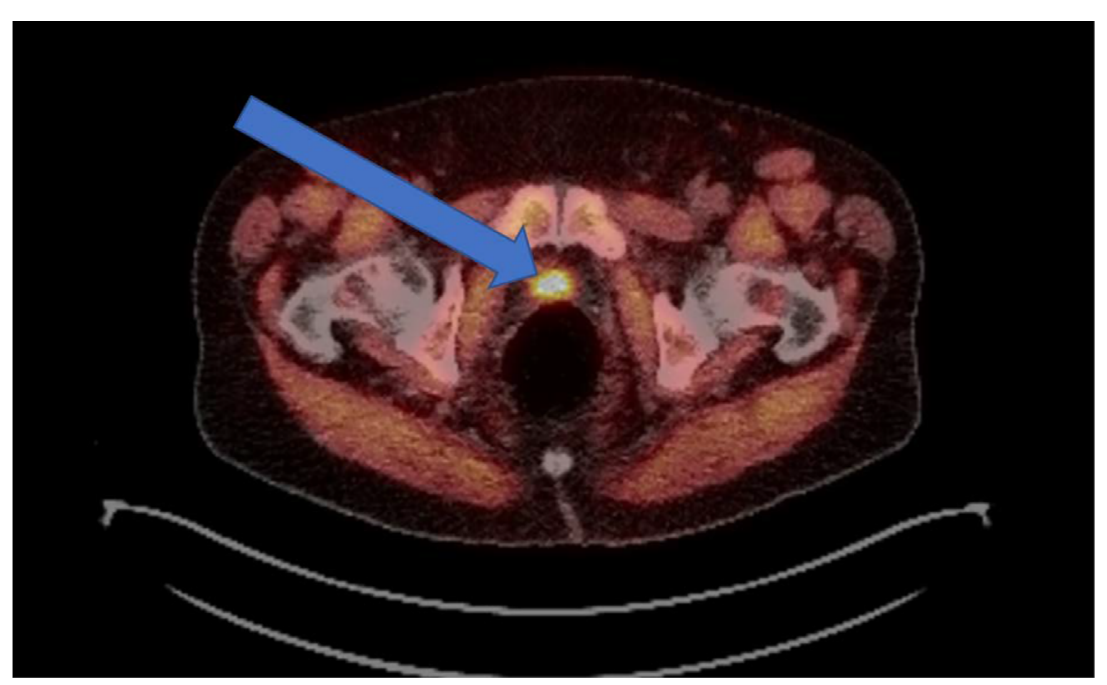

FIGURE 1 | Example of an ${ }^{18} \mathrm{~F}$-fluciclovine PET avid lesion in a biochemically recurrent prostate cancer patient. Demonstration of a $2.3-\mathrm{cm}{ }^{18} \mathrm{~F}$-fluciclovine PET-avid lesion in the prostatectomy bed. Patient was post-radical prostatectomy and presented with a PSA of $0.84 \mathrm{ng} / \mathrm{mL}$. 
define oligometastatic disease as $\leq 5$ metastases (89). In this space with evidence of overall limited disease, stereotactic ablative radiation therapy (SABR) may become a part of regular treatment management.

Both the HORRAD (90) and STAMPEDE (91) trials evaluated the role of definitive local treatment to the primary prostate in the setting of metastatic disease. In both trials, there was no difference in overall survival with the use of prostate primary-directed radiation therapy. However, on subgroup analysis in HORRAD, there was a trend toward benefit in overall survival with radiation therapy in men with low metastatic burden (defined as $\leq 5$ metastases, HR 0.68, 95\% CI $0.42-1.10$ ). Based on this, analysis by metastatic burden was a prespecified subgroup analysis in STAMPEDE. The subgroup analysis met many of the subgroup analysis criteria put forth by Sun et al. (92). Aa survival benefit was found in favor of primary prostate radiotherapy in men with $\leq 3$ metastases (HR $0.68,95 \%$ CI $0.52-0.90, \mathrm{p}=0.0098$ ). A secondary analysis of this trial demonstrated a significant survival benefit in patients with lymph node only metastases (HR 0.60, 95\% CI 0.33-1.09) as well as a failure-free survival benefit beyond 4 bone metastases up to 8 bone metastases (93). Overall, these are encouraging results but need to be further evaluated prospectively, particularly with new imaging modalities.

With respect to treatment of the metastatic lesions rather than the primary, the STOMP trial evaluated the benefit of metastasisdirected therapy (MDT, either surgery or radiation) in patients with biochemical recurrence after primary prostate treatment and $\leq 3$ metastases, with a primary endpoint of ADT-free survival (94). After a median follow-up of 3 years, aggressive metastasisdirected therapy did increase ADT-free survival (median ADTfree survival was 13 months [80\% CI 12-17 months] for surveillance versus 21 months [80\% CI 14-29 months] in MDT group, $\mathrm{p}=0.11$ ). Separately, the ORIOLE trial, a randomized phase 2 trial, evaluated observation versus SABR to metastatic disease in men with 1-3 metastases, found that, with a median follow-up of 18.8 months, SABR improved median progressionfree survival (PFS, not reached versus 5.8 months, HR 0.30, 95\% CI 0.11-0.81, $\mathrm{p}=0.0023$ ) (95). This trial incorporated the use of PSMA-PET, thus this is a contemporary evaluation of SABR in the oligometastatic disease space. More work needs to be performed to further define oligometastatic disease (number of metastases, oligoprogressive versus oligorecurrent, etc), understand the benefit of treatment to the primary versus metastases (versus both), benefit in setting of standard and escalated therapies, and others, but there remain many exciting opportunities for exploration into these questions to define the role of radiation therapy in this space.

\section{BLADDER CANCER}

There are two standard treatment options for muscle-invasive bladder cancer: 1) radical cystectomy, and 2) bladder preservation therapy (or trimodality therapy, TMT). Bladder preservation therapy is comprised of a combination of maximal transurethral resection of bladder tumor (TURBT), followed by chemoradiation. Molecular understanding of individual muscleinvasive bladder tumors may lead to predictive and prognostic biomarkers that can aid with treatment selection for individuals. Already, there are several promising candidates (96).

Bladder tumors frequently display mutations in DNA repair pathways, which likely drive bladder tumor development (97). MRE11 has demonstrated promise as a biomarker of radiation response. One study evaluated immunohistochemical staining of MRE11 in a cohort of patients treated with radiation alone (98). It was determined that patients with the lowest amounts of MRE11 staining had an associated worse 3-year cancer-specific survival. This was validated in a study evaluating MRE11 expression in tissues from 6 NRG/RTOG bladder-sparing radiation protocols. Low levels of MRE11 nuclear/cytoplasmic expression scores were associated with significantly higher diseasespecific mortality (99). Other groups have demonstrated a similar association. Laurberg et al. demonstrated low MRE11 staining was associated with worse disease-specific survival in a cohort of 148 patients treated with bladder preservation (100). They also found no associated with MRE11 staining and outcomes among patients who were treated with cystectomy. In a study by Teo et al., a single-nucleotide polymorphism (SNP) in the MRE11A gene was associated with worse outcomes among patients treated with radiation therapy, but not among patients treated with cystectomy (101). Interestingly, this SNP was not associated with increased or decreased MRE11 measured by immunohistochemistry.

Further investigations into DNA repair pathway alterations have been performed more often in cohorts of those who received neoadjuvant chemotherapy followed by cystectomy or in those with metastatic disease. However, a small study of 48 patients treated with bladder preservation found deleterious mutations in DNA repair pathways, in particular, ERCC2, were associated with improved outcomes after chemoradiation (102). More work needs to be done in bladder preservationspecific cohorts.

Separately, alterations in signal transduction pathways have also been implicated in bladder preservation. In a study using patients enrolled in four prospective bladder preservation studies (RTOG 8802, 8903, 9506, 9706), EGFR expression assessed by immunohistochemistry was associated with improved outcomes in both univariate and multivariate analyses. Conversely, HER2 expression via immunohistochemistry was associated with poorer outcomes, specifically with reduction in complete response after chemoradiation (103). This latter finding was confirmed by Inoue et al. in a cohort of 119 patients treated with bladder preservation therapy (104). HER2 overexpression was associated with pathologic incomplete response and worse cancer-specific survival, suggesting resistance to chemoradiation. The RTOG 0524 phase I/II trial evaluated the use of trastuzumab in patients who were HER2/neu 2+ or 3+ along with concurrent paclitaxel and radiation, versus radiation and concurrent paclitaxel in patients who were HER2/neu-negative or $1+$ by immunohistochemistry (105). It was found that both groups had similar complete response rates, thus suggesting that in patients 
with HER2/neu $2+$ or $3+$ expressing tumors, the addition of trastuzumab mitigated the previously associated worse prognosis. This finding needs to be further evaluated in a randomized study but demonstrates the ability of biomarkerdriven trials to improve outcomes in challenging diseases.

There has been work defining various molecular subtypes based on gene expression profiles (106-110). The subtypes, broadly characterized based on luminal and basal gene expression patterns, have been correlated with response to treatments including cystectomy and neoadjuvant chemotherapy. However, their association with response to chemoradiation is not clear. In one of the largest studies of molecular subtypes within a cohort of patients receiving bladder preservation therapy, specifically TMT, four subtypes were described, luminal, luminal-infiltrated, basal, and claudin-low (111). There was no association with complete response, diseasespecific survival or overall survival within the cohort. Further investigation and validation with other TMT/bladder preservation cohorts is necessary.

In patients who are not eligible for concurrent chemotherapy, the use of carbogen and nicotinamide to modify hypoxia in tumors resulted in improved survival compared to radiation alone in the BCON trial (112). Upon further analysis by molecular subtype, patients with a basal subtype had greater benefit with hypoxia modification while those with a luminal subtype had no benefit (113). A 24-gene hypoxia signature was developed and validated in the BCON cohort and found that patients with "high-hypoxia" per the signature had improved outcomes compared to those with "low-hypoxia" with the use of hypoxia modification (114). Both the hypoxia signature as well as the molecular subtype have yet to be validated prospectively to guide use of hypoxia modification but serve as early tools to aid in development of future trials.

Finally, identifying biomarkers related to immune checkpoint inhibition (ICI) response in muscle-invasive bladder cancer is of critical importance, particularly given the potential for improved response when combining ICIs with radiation therapy. There are multiple ongoing clinical investigations into the potential synergy of combination ICI + radiation therapy in this patient population. The aforementioned work evaluating molecular subtypes within a cohort of patients receiving TMT also evaluated immune signatures based on gene expression, finding that signatures associated with T-cell activation and interferon-gamma signaling were associated with improved disease-specific survival in the TMT cohort (111). In a comparison cohort of patients with muscle-invasive bladder cancer treated with neoadjuvant chemotherapy and radical cystectomy, this association did not hold. These promising data demonstrate that immune-related biomarkers may have implications for TMT in muscle-invasive bladder cancer, and potentially the combination of TMT + ICIs. This will need to be further examined in the ongoing trials evaluating TMT + ICI, such as the INTACT: SWOG/NRG 1806 study, evaluating chemoradiotherapy +/- atezolizumab in muscle-invasive bladder cancer (NCT03775265); the KEYNOTE-992 study, evaluating chemoradiotherapy $+/$ - pembrolizumab in muscle- invasive bladder cancer (NCT04241185); the CCTG BL13 trial, evaluating chemoradiotherapy followed by +/- adjuvant durvalumab; and the INSPIRE: ECOG-ACRIN/NRG EA8185 trial, evaluating chemoradiation $+/$ - durvalumab in nodepositive urothelial carcinoma (NCT04216290).

Liquid biopsy tools such as CTCs and ctDNA are similarly being investigated as prognostic biomarkers in bladder cancer as they are in prostate cancer $(115,116)$. CTCs and ctDNA will be collected and assessed in both the abovementioned INTACT and INSPIRE trials to determine their role as predictive biomarkers for overall outcomes after bladder preservation therapy. The presence of circulating biomarkers is also being explored in the surveillance setting post-treatment. One study in patients undergoing neoadjuvant chemotherapy followed by radical cystectomy found that the presence of ctDNA was prognostic for worse outcomes overall (115). This has not yet been evaluated in a TMT cohort but the data from INTACT and INSPIRE will help elucidate the role of liquid biomarkers in TMTspecific cohorts.

\section{Advances in Radiotherapy Techniques, Treatment Delivery}

Advances in image-guidance for radiation therapy has facilitated both dose escalation, hypofractionation, and adaptive planning for bladder cancer patients. Older trials evaluated multiple options for radiation dose, fields, and frequency of radiation treatment, thus there is no standard at this time. The INTACT trial is very inclusive and allows a variety of radiation fields, per physician discretion. Regarding dose, a recent meta-analysis of two randomized, controlled, phase 3 trials in the UK demonstrated that a hypofractionated schedule of 55 Gy in 20 fractions is non-inferior to conventional fractionation (64 Gy in 32 fractions) (117). However, there appears to be a non-trivial increase in unacceptable gastrointestinal grade 3 toxicity when using hypofractionation in combination with immune checkpoint inhibitors, based on results from a phase I trial of atezolizumab and chemoradiation (50 Gy/20 fractions) for muscle-invasive bladder cancer (118) as well as a phase I trial of pembrolizumab and weekly radiation of 6 Gy per fraction to a dose of 36 Gy (119). Both trials had a small number of patients ( $n=8$ and 5 respectively), and both were stopped early due to the dose-limiting toxicities observed. Thus, at this time, the INTACT trial uses conventional fractionation to avoid events that may contribute to dose-limiting toxicities.

To better delineate the primary bladder tumor, other imaging modalities are being explored that may aid in tumor-directed treatment. FDG-PET/CT may improve initial staging to better select patients for TMT, but physiologic uptake in the bladder limits its ability to better delineate the bladder tumor $(120,121)$. Multiparametric MRI is being explored to improve bladder tumor staging with advanced identification of muscle-invasion. MRI may also improve response assessment after bladder preservation therapy (122-125). At this time, further work is necessary to define the role of multiparametric MRI in the management of muscle-invasive bladder cancer. 
Ongoing trials are evaluating the utility of adaptive planning for treatment of advanced bladder cancer. One such trial is the RAIDER study (NCT02447549), which is a randomized phase II trial of either standard planning and radiation delivery, adaptive image guided tumor-focused radiation, or adaptive image guided dose-escalated tumor boost radiation. The primary endpoint is the proportion of patients meeting radiation dose constraints to the bladder, bowel, and rectum in the dose-escalated group, as well as the proportion of patients experiencing severe late side effects following treatment.

In the field of precision oncology, there are many exciting opportunities for radiation in the treatment of muscle-invasive bladder cancer. As ongoing trials start to close and more study into potential biomarkers is completed, the resulting data will aid in our improved selection and treatment of candidates for bladder-preservation.

\section{TESTICULAR CANCER}

In testicular seminoma, current treatment approaches have made this disease highly curable. Historically, radiation was the primary treatment for this disease, but the preferred treatment landscape has changed. For stage I seminoma, active surveillance is now the preferred treatment option (126). Emphasis on biomarkers of recurrence is necessary, as there are no current clinicopathologic variables that can be relied upon. Serum tumor markers are rarely elevated in a recurrence setting, and multiple studies suggest that they are unnecessary during surveillance follow-up $(127,128)$. Tumor size has been suggested as a risk factor for recurrence, however data is mixed on its prognostic ability $(129,130)$. miRNAs have demonstrated early promise as both diagnostic and prognostic markers $(131,132)$ but validation is required. The surveillance strategy consists of frequent computed tomography scans and follow-up. Yet, the seminoma population is very young, thus there is an emphasis to minimize irradiation. The Trial of Imaging and Surveillance in Seminoma Testis (TRISST, NCT00589537) evaluated the utility of decreased number of scans (from 7 to 3 ) as well as replacing CT scans with MRI (133). Results were recently presented at the 2021 GU Cancers Symposium and found that MRI is noninferior to CT, and thus should be recommended, and a 3-scan schedule is non-inferior to 7 scans. The surveillance paradigm will likely shift given these recent findings, and this trial reaffirms that surveillance is both safe and effective in stage I seminoma.

For early stage II disease (specifically stage IIA), treatment options include either radiation therapy or chemotherapy (typically 3-4 cycles of etoposide/cisplatin/bleomycin). Radiation therapy is preferred over chemotherapy given the favorable tolerability and toxicity profile (126). However, greater precision is needed with selection of treatment. There are currently no tools to help inform the decision between radiation or chemotherapy in this clinical setting.

When radiation therapy is indicated, there have been efforts to further limit radiation dose to organs-at-risk in this young population. Originally, radiation was delivered using 30 Gy in 15 fractions in the adjuvant setting. Yet, the recognition of seminoma as highly radiosensitive led to the pivotal trial exploring $30 \mathrm{~Gy} / 15$ fractions versus $20 \mathrm{~Gy}$ in 10 fractions (134). After a median follow-up of 61 months, it was determined that 20 Gy was just as effective and non-inferior to 30 Gy. Further reduction in dose to organs-at-risk may be accomplished using proton beam therapy. Proton beam technology is a promising treatment modality for this patient population given its unique physical characteristics. A recent study comparing patients between proton beam therapy and photon-based treatment demonstrated excellent outcomes and no in-field secondary malignancies (135), although this data is limited with only 55 patients included and a median follow-up of 61 months. Separately, a dosimetric modeling study demonstrated superior sparing of organs-at-risk with protons as compared to photons. Proton beam therapy was estimated to avert 300 excess second cancers among 10,000 men treated at a median age of 39 and surviving to age 75 (136). Proton beam therapy should be strongly considered and further evaluated for men with testicular seminoma.

Decreased field size has been highlighted specifically to further limit dose to organs-at-risk. Emphasis on decreasing field size was evaluated in a trial for stage I testicular seminoma patients, randomizing patients to either a para-aortic strip or ipsilateral iliac lymph node irradiation (dog-leg field) (137). After a median follow-up of 4.5 years, the para-aortic strip was non-inferior to the dog-leg field and reduced toxicity; it is now accepted as standard-of-care for adjuvant radiation treatment for stage I seminoma. More recently, an analysis of metastatic lymph node positives respective to vascular anatomy was performed in seminoma patients and suggested modified treatment fields based on vascular anatomy to decrease normal tissue irradiation (138). This study demonstrated that the superior border of the treatment field can safely be decreased from the T10/T11 interspace to the T11/T12 interspace. In addition, this has led to a greater emphasis on tailored nodal treatment fields based on vascular, rather than bony, anatomy.

Overall, more work is needed in the field of biomarkers for testicular cancer, particularly as it relates to radiotherapy, in the surveillance setting, for treatment selection and for response to treatment.

\section{RENAL CELL CARCINOMA}

The management of renal cell carcinoma (RCC) has been revolutionized by targeted kinase inhibitors (TKIs) as well as immunotherapy. Traditionally, RCC was deemed "radioresistant" and the role for radiation therapy was limited to mostly palliation. However, the rapid advancement of on-treatment image guidance, as well as highly conformal techniques to deliver a high-dose-per-fraction, has paved the way for stereotactic ablative radiation therapy ( $\mathrm{SABR}$ ) to play a role in definitive treatment of RCC (139-141). A 2019 meta-analysis of 26 studies targeting primary RCC with SABR demonstrated excellent local control and low grade 3-4 toxicity rates (142). 
Regarding kidney function, a prior study of 21 patients with inoperable RCC demonstrated reasonable change in mean GFR at 2 weeks $(+0.6+/-11.3 \mathrm{ml} / \mathrm{min}), 3$ months $(+3.2+/-14.5 \mathrm{ml} /$ $\mathrm{min})$, and 1 year $(-8.7+/-13.4 \mathrm{ml} / \mathrm{min})(143)$. Ongoing trials are further evaluating the safety and efficacy of SABR to primary RCC (NCT02853162, NCT03108703, NCT01890590, NCT02613819, NCT03747133) and will help to establish the role of SABR for primary RCC.

Separately, there are numerous studies demonstrating a potential synergistic antitumor effect with SABR in combination with targeted therapies for metastatic RCC (mRCC). For example, SABR to an "oligoprogressive" lesion was found to extend the efficacy of sunitinib from 14 to 22 days (141). There is a lot of interest and ongoing trials evaluating the efficacy of combined immunotherapy with radiation, given case reports that have described an observed abscopal effect in the setting of both radiation and immune checkpoint inhibition (144). The phase II NIVES study (NCT03469713) is a singlearm study, evaluating the role of SABR to metastatic lesions in mRCC patients who receive nivolumab. Early data demonstrate a median PFS of 4 months, which is not much different from the nivolumab alone arm on CheckMate025, a trial randomizing mRCC patients to nivolumab versus everolimus (145). The RADVAX trial (NCT03065179) is a single-arm study evaluating the role of SABR to metastases in mRCC patients who receive both nivolumab and ipilumumab, with a median PFS of 8.2 months thus far. This is also not much different from the nivolumab + ipilumumab arm in CheckMate214, which randomized mRCC patients to either dual checkpoint inhibition or sunitinib (146). However, in the RAPPORT trial that was presented at the recent 2021 GU Cancers Symposium, patients with low burden of metastases received SABR (20 Gy x 1) and pembrolizumab (147). The treatment was well tolerated and the median PFS was 15.6 months, which is improved over the KEYNOTE-427 trial of pembrolizumab monotherapy (PFS of 7.1 months). Further work is necessary to understand appropriate patient selection to a confer a benefit for SABR. The CYTOSHRINK trial is a phase II trial of nivolumab and

\section{REFERENCES}

1. D’Amico AV, Schnall M, Whittington R, Malkowicz SB, Schultz D, Tomaszewski JE, et al. Endorectal Coil Magnetic Resonance Imaging Identifies Locally Advanced Prostate Cancer in Select Patients With Clinically Localized Disease. Urology (1998) 51(3):449-54. doi: 10.1016/ S0090-4295(97)00630-4

2. Wagenlehner FM, van Oostrum E, Tenke P, Tandogdu Z, Çek M, Grabe M, et al. Infective Complications After Prostate Biopsy: Outcome of the Global Prevalence Study of Infections in Urology (GPIU) 2010 and 2011, a Prospective Multinational Multicentre Prostate Biopsy Study. Eur Urol (2013) 63(3):521-7. doi: 10.1016/j.eururo.2012.06.003

3. Engelbrecht MR, Puech P, Colin P, Akin O, Lemaître L, Villers A. Multimodality Magnetic Resonance Imaging of Prostate Cancer. J Endourol (2010) 24(5):677-84. doi: 10.1089/end.2009.0597

4. Hegde JV, Mulkern RV, Panych LP, Fennessy FM, Fedorov A, Maier SE, et al. Multiparametric MRI of Prostate Cancer: An Update on State-of-theArt Techniques and Their Performance in Detecting and Localizing Prostate Cancer. J Magnetic Resonance Imaging JMRI (2013) 37(5):1035-54. doi: 10.1002/jmri.23860 ipilumumab +/- SABR to the primary RCC in mRCC patients (NCT04090710). Other trials are being opened in this space to evaluate the role of SABR to the primary or the primary + metastases in combination with immune checkpoint inhibitors to potentiate the effect of immunotherapy and improve outcomes in this disease space.

\section{SUMMARY}

Advances in technology have led to a greater understanding of the molecular characterization of genitourinary cancers. Separately, developments in radiation therapy have led to improved tumor targeting as well as decreased dose to surrounding normal tissues. However, there is an urgent need to incorporate molecular information about various genitourinary malignancies to personalize radiation treatment. Just in the past few years, considerable progress has been made within the GU field with many promising biomarkers that have the potential to optimize radiation management that need to be validated. There remain many exciting opportunities for biomarker discovery as well as a need to validate the utility of biomarkers into initial management of genitourinary malignancies. We advocate for the incorporation of known tumor biomarkers into prospective clinical trials as well as for incorporation of translational studies for further biomarker discovery. Continued effort is necessary to one day fully integrate tumor biology to inform management decisions, with the ultimate goal of improving outcomes for our patients.

\section{AUTHOR CONTRIBUTIONS}

Concept and design: SK and JE. Drafting of the manuscript: SK and JE. Critical revision of the manuscript for important intellectual content: SK and JE. All authors contributed to the article and approved the submitted version.

5. Rais-Bahrami S, Siddiqui MM, Vourganti S, Turkbey B, Rastinehad AR, Stamatakis L, et al. Diagnostic Value of Biparametric Magnetic Resonance Imaging (MRI) as an Adjunct to Prostate-Specific Antigen (PSA)-Based Detection of Prostate Cancer in Men Without Prior Biopsies. BJU Int (2015) 115(3):381-8. doi: 10.1111/bju.12639

6. Turkbey B, Mani H, Shah V, Rastinehad AR, Bernardo M, Pohida T, et al. Multiparametric 3T Prostate Magnetic Resonance Imaging to Detect Cancer: Histopathological Correlation Using Prostatectomy Specimens Processed in Customized Magnetic Resonance Imaging Based Molds. J Urol (2011) 186(5):1818-24. doi: 10.1016/j.juro.2011.07.013

7. Haffner J, Lemaitre L, Puech P, Haber GP, Leroy X, Jones JS, et al. Role of Magnetic Resonance Imaging Before Initial Biopsy: Comparison of Magnetic Resonance Imaging-Targeted and Systematic Biopsy for Significant Prostate Cancer Detection. BJU Int (2011) 108(8 Pt 2):E171-8. doi: 10.1111/j.1464-410X.2011.10112.x

8. Park BK, Park JW, Park SY, Kim CK, Lee HM, Jeon SS, et al. Prospective Evaluation of 3-T MRI Performed Before Initial Transrectal UltrasoundGuided Prostate Biopsy in Patients With High Prostate-Specific Antigen and No Previous Biopsy. AJR Am J Roentgenol (2011) 197(5):W876-81. doi: 10.2214/AJR.11.6829 
9. Puech P, Rouvière O, Renard-Penna R, Villers A, Devos P, Colombel M, et al. Prostate Cancer Diagnosis: Multiparametric MR-targeted Biopsy With Cognitive and Transrectal US-MR Fusion Guidance Versus Systematic Biopsy-Prospective Multicenter Study. Radiology (2013) 268(2):461-9. doi: 10.1148/radiol.13121501

10. Siddiqui MM, Rais-Bahrami S, Turkbey B, George AK, Rothwax J, Shakir N, et al. Comparison of MR/ultrasound Fusion-Guided Biopsy With Ultrasound-Guided Biopsy for the Diagnosis of Prostate Cancer. Jama (2015) 313(4):390-7. doi: 10.1001/jama.2014.17942

11. Sonn GA, Chang E, Natarajan S, Margolis DJ, Macairan M, Lieu P, et al. Value of Targeted Prostate Biopsy Using Magnetic Resonance-Ultrasound Fusion in Men With Prior Negative Biopsy and Elevated Prostate-Specific Antigen. Eur Urol (2014) 65(4):809-15. doi: 10.1016/j.eururo.2013. 03.025

12. Klotz L, Chin J, Black PC, Finelli A, Anidjar M, Bladou F, et al. Comparison of Multiparametric Magnetic Resonance Imaging-Targeted Biopsy With Systematic Transrectal Ultrasonography Biopsy for Biopsy-Naive Men At Risk for Prostate Cancer: A Phase 3 Randomized Clinical Trial. JAMA Oncol (2021)7:534-42. doi: 10.1001/jamaoncol.2020.7589

13. Loeb S, Catalona WJ. The Prostate Health Index: A New Test for the Detection of Prostate Cancer. Ther Adv Urol (2014) 6(2):74-7. doi: 10.1177/ 1756287213513488

14. Zappala SM, Scardino PT, Okrongly D, Linder V, Dong Y. Clinical Performance of the 4Kscore Test to Predict High-Grade Prostate Cancer At Biopsy: A Meta-Analysis of Us and European Clinical Validation Study Results. Rev Urol (2017) 19(3):149-55. doi: 10.3909/riu0776

15. Marks LS, Fradet Y, Deras IL, Blase A, Mathis J, Aubin SM, et al. PCA3 Molecular Urine Assay for Prostate Cancer in Men Undergoing Repeat Biopsy. Urology (2007) 69(3):532-5. doi: 10.1016/j.urology.2006.12.014

16. Tomlins SA, Aubin SM, Siddiqui J, Lonigro RJ, Sefton-Miller L, Miick S, et al. Urine TMPRSS2:ERG Fusion Transcript Stratifies Prostate Cancer Risk in Men With Elevated Serum PSA. Sci Trans Med (2011) 3(94):94ra72. doi: 10.1126/scitranslmed.3001970

17. Petrovics G, Liu A, Shaheduzzaman S, Furusato B, Sun C, Chen Y, et al. Frequent Overexpression of ETS-related Gene-1 (ERG1) in Prostate Cancer Transcriptome. Oncogene (2005) 24(23):3847-52. doi: 10.1038/sj.onc.1208518

18. Rubin MA, Maher CA, Chinnaiyan AM. Common Gene Rearrangements in Prostate Cancer. J Clin Oncol (2011) 29(27):3659-68. doi: 10.1200/ JCO.2011.35.1916

19. Farsad M, Schiavina R, Castellucci P, Nanni C, Corti B, Martorana G, et al. Detection and Localization of Prostate Cancer: Correlation of (11)C-Choline PET/CT With Histopathologic Step-Section Analysis. J Nucl Med Off Publication Soc Nucl Med (2005) 46(10):1642-9.

20. Nanni C, Schiavina R, Brunocilla E, Boschi S, Borghesi M, Zanoni L, et al. 18f-Fluciclovine PET/CT for the Detection of Prostate Cancer Relapse: A Comparison to 11C-Choline Pet/Ct. Clin Nucl Med (2015) 40(8):e386-91. doi: 10.1097/RLU.0000000000000849

21. Fendler WP, Schmidt DF, Wenter V, Thierfelder KM, Zach C, Stief C, et al. 68Ga-PSMA PET/CT Detects the Location and Extent of Primary Prostate Cancer. J Nucl Med Off Publication Soc Nucl Med (2016) 57(11):1720-5. doi: 10.2967/jnumed.116.172627

22. Rowe SP, Gage KL, Faraj SF, Macura KJ, Cornish TC, Gonzalez-Roibon N, et al. ${ }^{18} \mathrm{~F}$-Dcfbc PET/CT for PSMA-Based Detection and Characterization of Primary Prostate Cancer. J Nucl Med Off Publication Soc Nucl Med (2015) 56 (7):1003-10. doi: 10.2967/jnumed.115.154336

23. Hofman MS, Lawrentschuk N, Francis RJ, Tang C, Vela I, Thomas P, et al. Prostate-Specific Membrane Antigen PET-CT in Patients With High-Risk Prostate Cancer Before Curative-Intent Surgery or Radiotherapy (proPSMA): A Prospective, Randomised, Multicentre Study. Lancet (London England) (2020) 395(10231):1208-16. doi: 10.1016/S0140-6736 (20)30314-7

24. Calais J, Ceci F, Eiber M, Hope TA, Hofman MS, Rischpler C, et al. (18)FFluciclovine PET-CT and (68)Ga-PSMA-11 PET-CT in Patients With Early Biochemical Recurrence After Prostatectomy: A Prospective, Single-Centre, Single-Arm, Comparative Imaging Trial. Lancet Oncol (2019) 20(9):128694. doi: 10.1016/S1470-2045(19)30415-2

25. Schwarzenboeck SM, Rauscher I, Bluemel C, Fendler WP, Rowe SP, Pomper MG, et al. Psma Ligands for PET Imaging of Prostate Cancer. J Nucl Med Off
Publication Soc Nucl Med (2017) 58(10):1545-52. doi: 10.2967/ jnumed.117.191031

26. Dess RT, Suresh K, Zelefsky MJ, Freedland SJ, Mahal BA, Cooperberg MR, et al. Development and Validation of a Clinical Prognostic Stage Group System for Nonmetastatic Prostate Cancer Using Disease-Specific Mortality Results From the International Staging Collaboration for Cancer of the Prostate. JAMA Oncol (2020) 6(12):1912-20. doi: 10.1001/jamaoncol. 2020.4922

27. Cooperberg MR, Freedland SJ, Pasta DJ, Elkin EP, Presti JCJr., Amling CL, et al. Multiinstitutional Validation of the UCSF Cancer of the Prostate Risk Assessment for Prediction of Recurrence After Radical Prostatectomy. Cancer (2006) 107(10):2384-91. doi: 10.1002/cncr.22262

28. Cuzick J, Berney DM, Fisher G, Mesher D, Møller H, Reid JE, et al. Prognostic Value of a Cell Cycle Progression Signature for Prostate Cancer Death in a Conservatively Managed Needle Biopsy Cohort. $\mathrm{Br} J$ Cancer (2012) 106(6):1095-9. doi: 10.1038/bjc.2012.39

29. Cuzick J, Swanson GP, Fisher G, Brothman AR, Berney DM, Reid JE, et al. Prognostic Value of an RNA Expression Signature Derived From Cell Cycle Proliferation Genes in Patients With Prostate Cancer: A Retrospective Study. Lancet Oncol (2011) 12(3):245-55. doi: 10.1016/S1470-2045(10)70295-3

30. Cooperberg MR, Simko JP, Cowan JE, Reid JE, Djalilvand A, Bhatnagar S, et al. Validation of a Cell-Cycle Progression Gene Panel to Improve Risk Stratification in a Contemporary Prostatectomy Cohort. J Clin Oncol (2013) 31(11):1428-34. doi: 10.1200/JCO.2012.46.4396

31. Freedland SJ, Gerber L, Reid J, Welbourn W, Tikishvili E, Park J, et al. Prognostic Utility of Cell Cycle Progression Score in Men With Prostate Cancer After Primary External Beam Radiation Therapy. Int J Radiat Oncol Biol Phys (2013) 86(5):848-53. doi: 10.1016/j.ijrobp.2013.04.043

32. NICE ADVICE group. Nice Advice - Prolaris Gene Expression Assay for Assessing Long-Term Risk of Prostate Cancer Progression: (C) NICE (2016) Prolaris Gene Expression Assay for Assessing Long-Term Risk of Prostate Cancer Progression. BJU Int (2018) 122(2):173-80. doi: 10.1111/bju.14452

33. Blume-Jensen P, Berman DM, Rimm DL, Shipitsin M, Putzi M, Nifong TP, et al. Development and Clinical Validation of an in Situ Biopsy-Based Multimarker Assay for Risk Stratification in Prostate Cancer. Clin Cancer Res An Off J Am Assoc Cancer Res (2015) 21(11):2591-600. doi: 10.1158/ 1078-0432.CCR-14-2603

34. Klein EA, Cooperberg MR, Magi-Galluzzi C, Simko JP, Falzarano SM, Maddala T, et al. A 17-Gene Assay to Predict Prostate Cancer Aggressiveness in the Context of Gleason Grade Heterogeneity, Tumor Multifocality, and Biopsy Undersampling. Eur Urol (2014) 66(3):550-60. doi: 10.1016/j.eururo.2014.08.001

35. Cullen J, Rosner IL, Brand TC, Zhang N, Tsiatis AC, Moncur J, et al. A Biopsy-based 17-Gene Genomic Prostate Score Predicts Recurrence After Radical Prostatectomy and Adverse Surgical Pathology in a Racially Diverse Population of Men With Clinically Low- and Intermediate-risk Prostate Cancer. Eur Urol (2015) 68(1):123-31. doi: 10.1016/j.eururo.2014.11.030

36. Lin DW, Zheng Y, McKenney JK, Brown MD, Lu R, Crager M, et al. 17-Gene Genomic Prostate Score Test Results in the Canary Prostate Active Surveillance Study (Pass) Cohort. J Clin Oncol (2020) 38(14):1549-57. doi: 10.1200/JCO.19.02267

37. Dalela D, Santiago-Jiménez M, Yousefi K, Karnes RJ, Ross AE, Den RB, et al. Genomic Classifier Augments the Role of Pathological Features in Identifying Optimal Candidates for Adjuvant Radiation Therapy in Patients With Prostate Cancer: Development and Internal Validation of a Multivariable Prognostic Model. J Clin Oncol (2017) 35(18):1982-90. doi: 10.1200/JCO.2016.69.9918

38. Den RB, Feng FY, Showalter TN, Mishra MV, Trabulsi EJ, Lallas CD, et al. Genomic Prostate Cancer Classifier Predicts Biochemical Failure and Metastases in Patients After Postoperative Radiation Therapy. Int J Radiat Oncol Biol Phys (2014) 89(5):1038-46. doi: 10.1016/j.ijrobp.2014.04.052

39. Gore JL, du Plessis M, Santiago-Jiménez M, Yousefi K, Thompson DJS, Karsh L, et al. Decipher Test Impacts Decision Making Among Patients Considering Adjuvant and Salvage Treatment After Radical Prostatectomy: Interim Results From the Multicenter Prospective PRO-IMPACT Study. Cancer (2017) 123(15):2850-9. doi: 10.1002/cncr.30665

40. Marascio J, Spratt DE, Zhang J, Trabulsi EJ, Le T, Sedzorme WS, et al. Prospective Study to Define the Clinical Utility and Benefit of Decipher 
Testing in Men Following Prostatectomy. Prostate Cancer Prostatic Dis (2020) 23(2):295-302. doi: 10.1038/s41391-019-0185-7

41. Spratt DE, Yousefi K, Deheshi S, Ross AE, Den RB, Schaeffer EM, et al. Individual Patient-Level Meta-Analysis of the Performance of the Decipher Genomic Classifier in High-Risk Men After Prostatectomy to Predict Development of Metastatic Disease. J Clin Oncol (2017) 35(18):1991-8. doi: 10.1200/JCO.2016.70.2811

42. Kim HL, Li P, Huang HC, Deheshi S, Marti T, Knudsen B, et al. Validation of the Decipher Test for Predicting Adverse Pathology in Candidates for Prostate Cancer Active Surveillance. Prostate Cancer Prostatic Dis (2019) 22(3):399-405. doi: 10.1038/s41391-018-0101-6

43. Berlin A, Murgic J, Hosni A, Pintilie M, Salcedo A, Fraser M, et al. Genomic Classifier for Guiding Treatment of Intermediate-Risk Prostate Cancers to Dose-Escalated Image Guided Radiation Therapy Without Hormone Therapy. Int J Radiat Oncol Biol Phys (2019) 103(1):84-91. doi: 10.1016/ j.ijrobp.2018.08.030

44. Spratt DE, Zhang J, Santiago-Jiménez M, Dess RT, Davis JW, Den RB, et al. Development and Validation of a Novel Integrated Clinical-Genomic Risk Group Classification for Localized Prostate Cancer. J Clin Oncol (2018) 36 (6):581-90. doi: 10.1200/JCO.2017.74.2940

45. Feng FY, Huang HC, Spratt DE, Zhao SG, Sandler HM, Simko JP, et al. Validation of a 22-Gene Genomic Classifier in Patients With Recurrent Prostate Cancer: An Ancillary Study of the NRG/RTOG 9601 Randomized Clinical Trial. JAMA Oncol (2021)7(4):544-52. doi: 10.1001/ jamaoncol.2020.7671

46. Castro E, Romero-Laorden N, Del Pozo A, Lozano R, Medina A, Puente J, et al. Prorepair-B: A Prospective Cohort Study of the Impact of Germline Dna Repair Mutations on the Outcomes of Patients With Metastatic Castration-Resistant Prostate Cancer. J Clin Oncol (2019) 37(6):490-503. doi: 10.1200/JCO.18.00358

47. Grasso CS, Wu YM, Robinson DR, Cao X, Dhanasekaran SM, Khan AP, et al. The Mutational Landscape of Lethal Castration-Resistant Prostate Cancer. Nature (2012) 487(7406):239-43. doi: 10.1038/nature11125

48. Pritchard CC, Mateo J, Walsh MF, De Sarkar N, Abida W, Beltran H, et al. Inherited DNA-Repair Gene Mutations in Men With Metastatic Prostate Cancer. N Engl J Med (2016) 375(5):443-53. doi: 10.1056/NEJMoa1603144

49. Robinson D, Van Allen EM, Wu YM, Schultz N, Lonigro RJ, Mosquera JM, et al. Integrative Clinical Genomics of Advanced Prostate Cancer. Cell (2015) 161(5):1215-28. doi: 10.1016/j.cell.2015.06.053

50. Mateo J, Seed G, Bertan C, Rescigno P, Dolling D, Figueiredo I, et al. Genomics of Lethal Prostate Cancer At Diagnosis and Castration Resistance. J Clin Invest (2020) 130(4):1743-51. doi: 10.1172/JCI132031

51. de Bono J, Mateo J, Fizazi K, Saad F, Shore N, Sandhu S, et al. Olaparib for Metastatic Castration-Resistant Prostate Cancer. N Engl J Med (2020) 382 (22):2091-102. doi: 10.1056/NEJMoa1911440

52. Abida W, Campbell D, Patnaik A, Shapiro JD, Sautois B, Vogelzang NJ, et al. Non-BRCA DNA Damage Repair Gene Alterations and Response to the PARP Inhibitor Rucaparib in Metastatic Castration-Resistant Prostate Cancer: Analysis From the Phase Ii TRITON2 Study. Clin Cancer Res An Off J Am Assoc Cancer Res (2020) 26(11):2487-96. doi: 10.1158/1078-0432.CCR-20-0394

53. Cheng HH, Pritchard CC, Boyd T, Nelson PS, Montgomery B. Biallelic Inactivation of BRCA2 in Platinum-sensitive Metastatic Castration-resistant Prostate Cancer. Eur Urol (2016) 69(6):992-5. doi: 10.1016/j.eururo. 2015.11.022

54. González-Billalabeitia E, Conteduca V, Wetterskog D, Jayaram A, Attard G. Circulating Tumor DNA in Advanced Prostate Cancer: Transitioning From Discovery to a Clinically Implemented Test. Prostate Cancer Prostatic Dis (2019) 22(2):195-205. doi: 10.1038/s41391-018-0098-x

55. Mateo J, Carreira S, Sandhu S, Miranda S, Mossop H, Perez-Lopez R, et al. Dna-Repair Defects and Olaparib in Metastatic Prostate Cancer. N Engl J Med (2015) 373(18):1697-708. doi: 10.1056/NEJMoa1506859

56. Mateo J, Porta N, Bianchini D, McGovern U, Elliott T, Jones R, et al. Olaparib in Patients With Metastatic Castration-Resistant Prostate Cancer With DNA Repair Gene Aberrations (TOPARP-B): A Multicentre, OpenLabel, Randomised, Phase 2 Trial. Lancet Oncol (2020) 21(1):162-74. doi: 10.1016/S1470-2045(19)30684-9

57. Pomerantz MM, Spisák S, Jia L, Cronin AM, Csabai I, Ledet E, et al. The Association Between Germline BRCA2 Variants and Sensitivity to Platinum-
Based Chemotherapy Among Men With Metastatic Prostate Cancer. Cancer (2017) 123(18):3532-9. doi: 10.1002/cncr.30808

58. Zafeiriou Z, Bianchini D, Chandler R, Rescigno P, Yuan W, Carreira S, et al. Genomic Analysis of Three Metastatic Prostate Cancer Patients With Exceptional Responses to Carboplatin Indicating Different Types of DNA Repair Deficiency. Eur Urol (2019) 75(1):184-92. doi: 10.1016/ j.eururo.2018.09.048

59. Conteduca V, Wetterskog D, Sharabiani MTA, Grande E, Fernandez-Perez MP, Jayaram A, et al. Androgen Receptor Gene Status in Plasma DNA Associates With Worse Outcome on Enzalutamide or Abiraterone for Castration-Resistant Prostate Cancer: A Multi-Institution Correlative Biomarker Study. Ann Oncol Off J Eur Soc Med Oncol (2017) 28(7):150816. doi: 10.1093/annonc/mdx155

60. Antonarakis ES, Lu C, Luber B, Wang H, Chen Y, Nakazawa M, et al. Androgen Receptor Splice Variant 7 and Efficacy of Taxane Chemotherapy in Patients With Metastatic Castration-Resistant Prostate Cancer. JAMA Oncol (2015) 1(5):582-91. doi: 10.1001/jamaoncol.2015.1341

61. Antonarakis ES, Lu C, Luber B, Wang H, Chen Y, Zhu Y, et al. Clinical Significance of Androgen Receptor Splice Variant-7 Mrna Detection in Circulating Tumor Cells of Men With Metastatic Castration-Resistant Prostate Cancer Treated With First- and Second-Line Abiraterone and Enzalutamide. J Clin Oncol (2017) 35(19):2149-56. doi: 10.1200/ JCO.2016.70.1961

62. Antonarakis ES, Lu C, Wang H, Luber B, Nakazawa M, Roeser JC, et al. ArV7 and Resistance to Enzalutamide and Abiraterone in Prostate Cancer. N Engl J Med (2014) 371(11):1028-38. doi: 10.1056/NEJMoa1315815

63. Scher HI, Graf RP, Schreiber NA, McLaughlin B, Lu D, Louw J, et al. Nuclear-Specific AR-V7 Protein Localization is Necessary to Guide Treatment Selection in Metastatic Castration-Resistant Prostate Cancer. Eur Urol (2017) 71(6):874-82. doi: 10.1016/j.eururo.2016.11.024

64. Ahearn TU, Pettersson A, Ebot EM, Gerke T, Graff RE, Morais CL, et al. A Prospective Investigation of PTEN Loss and ERG Expression in Lethal Prostate Cancer. J Natl Cancer Institute (2016) 108(2):djv346. doi: 10.1093/ jnci/djv346

65. Miyamoto DT, Lee RJ. Cell-Free and Circulating Tumor Cell-Based Biomarkers in Men With Metastatic Prostate Cancer: Tools for Real-Time Precision Medicine? Urol Oncol (2016) 34(11):490-501. doi: 10.1016/ j.urolonc.2016.09.001

66. Broncy L, Paterlini-Bréchot P. Clinical Impact of Circulating Tumor Cells in Patients With Localized Prostate Cancer. Cells (2019) 8(7):676. doi: 10.3390/ cells 8070676

67. Rangel-Pozzo A, Liu S, Wajnberg G, Wang X, Ouellette RJ, Hicks GG, et al. Genomic Analysis of Localized High-Risk Prostate Cancer Circulating Tumor Cells At the Single-Cell Level. Cells (2020) 9(8):1863. doi: 10.3390/ cells 9081863

68. Mariados N, Sylvester J, Shah D, Karsh L, Hudes R, Beyer D, et al. Hydrogel Spacer Prospective Multicenter Randomized Controlled Pivotal Trial: Dosimetric and Clinical Effects of Perirectal Spacer Application in Men Undergoing Prostate Image Guided Intensity Modulated Radiation Therapy. Int J Radiat Oncol Biol Phys (2015) 92(5):971-7. doi: 10.1016/ j.ijrobp.2015.04.030

69. Miller LE, Efstathiou JA, Bhattacharyya SK, Payne HA, Woodward E, Pinkawa M. Association of the Placement of a Perirectal Hydrogel Spacer With the Clinical Outcomes of Men Receiving Radiotherapy for Prostate Cancer: A Systematic Review and Meta-Analysis. JAMA Netw Open (2020) 3 (6):e208221. doi: 10.1001/jamanetworkopen.2020.8221

70. Ma TM, Lilleby O, Lilleby WA, Kishan AU. Ablative Radiotherapy in Prostate Cancer: Stereotactic Body Radiotherapy and High Dose Rate Brachytherapy. Cancers (2020) 12(12):3606. doi: 10.3390/cancers12123606

71. Morgan SC, Hoffman K, Loblaw DA, Buyyounouski MK, Patton C, Barocas D, et al. Hypofractionated Radiation Therapy for Localized Prostate Cancer: Executive Summary of an ASTRO, ASCO and AUA Evidence-Based Guideline. J Urol (2019) 201(3):528-34. doi: 10.1097/JU.0000000000000071

72. Wolf F, Sedlmayer F, Aebersold D, Albrecht C, Böhmer D, Flentje M, et al. Ultrahypofractionation of Localized Prostate Cancer: Statement From the DEGRO Working Group Prostate Cancer. Strahlentherapie Und Onkologie: Organ Der Deutschen Rontgengesellschaft. (2021) 197(2):89-96. [et al]. doi: 10.1007/s00066-020-01723-8 
73. Catton CN, Lukka H, Gu CS, Martin JM, Supiot S, Chung PWM, et al. Randomized Trial of a Hypofractionated Radiation Regimen for the Treatment of Localized Prostate Cancer. J Clin Oncol (2017) 35(17):188490. doi: 10.1200/JCO.2016.71.7397

74. Incrocci L, Wortel RC, Alemayehu WG, Aluwini S, Schimmel E, Krol S, et al. Hypofractionated Versus Conventionally Fractionated Radiotherapy for Patients With Localised Prostate Cancer (HYPRO): Final Efficacy Results From a Randomised, Multicentre, Open-Label, Phase 3 Trial. Lancet Oncol (2016) 17(8):1061-9. doi: 10.1016/S1470-2045(16)30070-5

75. Dearnaley D, Syndikus I, Mossop H, Khoo V, Birtle A, Bloomfield D, et al. Conventional Versus Hypofractionated High-Dose Intensity-Modulated Radiotherapy for Prostate Cancer: 5-Year Outcomes of the Randomised, non-Inferiority, Phase 3 CHHiP Trial. Lancet Oncol (2016) 17(8):1047-60. doi: 10.1016/S1470-2045(16)30102-4

76. Lee WR, Dignam JJ, Amin MB, Bruner DW, Low D, Swanson GP, et al. Randomized Phase Iii Noninferiority Study Comparing Two Radiotherapy Fractionation Schedules in Patients With Low-Risk Prostate Cancer. J Clin Oncol (2016) 34(20):2325-32. doi: 10.1200/JCO.2016.67.0448

77. Hoffman KE, Voong KR, Levy LB, Allen PK, Choi S, Schlembach PJ, et al. Randomized Trial of Hypofractionated, Dose-Escalated, IntensityModulated Radiation Therapy (Imrt) Versus Conventionally Fractionated IMRT for Localized Prostate Cancer. J Clin Oncol (2018) 36(29):2943-9. doi: 10.1200/JCO.2018.77.9868

78. Widmark A, Gunnlaugsson A, Beckman L, Thellenberg-Karlsson C, Hoyer M, Lagerlund M, et al. Ultra-Hypofractionated Versus Conventionally Fractionated Radiotherapy for Prostate Cancer: 5-Year Outcomes of the HYPO-RT-PC Randomised, non-Inferiority, Phase 3 Trial. Lancet (London England) (2019) 394(10196):385-95. doi: 10.1016/S0140-6736(19)31131-6

79. Brand DH, Tree AC, Ostler P, van der Voet H, Loblaw A, Chu W, et al. Intensity-Modulated Fractionated Radiotherapy Versus Stereotactic Body Radiotherapy for Prostate Cancer (PACE-B): Acute Toxicity Findings From an International, Randomised, Open-Label, Phase 3, non-Inferiority Trial. Lancet Oncol (2019) 20(11):1531-43. doi: 10.1016/S1470-2045(19)30569-8

80. Lukka HR, Pugh SL, Bruner DW, Bahary JP, Lawton CAF, Efstathiou JA, et al. Patient Reported Outcomes in NRG Oncology RTOG 0938, Evaluating Two Ultrahypofractionated Regimens for Prostate Cancer. Int J Radiat Oncol Biol Phys (2018) 102(2):287-95. doi: 10.1016/j.ijrobp.2018.06.008

81. Kerkmeijer LGW, Groen VH, Pos FJ, Haustermans K, Monninkhof EM, Smeenk RJ, et al. Focal Boost to the Intraprostatic Tumor in External Beam Radiotherapy for Patients With Localized Prostate Cancer: Results From the FLAME Randomized Phase Iii Trial. J Clin Oncol (2021) 39(7):787-96. doi: $10.1200 / J C O .20 .02873$

82. Kamran SC, Light JO, Efstathiou JA. Proton Versus Photon-Based Radiation Therapy for Prostate Cancer: Emerging Evidence and Considerations in the Era of Value-Based Cancer Care. Prostate Cancer Prostatic Dis (2019) 22 (4):509-21. doi: 10.1038/s41391-019-0140-7

83. Vapiwala N, Wong JK, Handorf E, Paly J, Grewal A, Tendulkar R, et al. A Pooled Toxicity Analysis of Moderately Hypofractionated Proton Beam Therapy and Intensity-Modulated Radiation Therapy in Early Stage Prostate Cancer Patients. Int J Radiat Oncol Biol Phys (2021) S0360-3016(21):001176. doi: 10.1016/j.ijrobp.2021.01.043

84. Menard C, Delouya G, Wong P, Beauchemin MC, Barkati M, Taussky D, et al. Randomized Controlled Trial of PSMA Pet/Ct Guided Intensification of Radiotherapy for Prostate Cancer: Detection Rates and Impact on Radiotherapeutic Management. Int J Radiat Oncol Biol Phys (2020) 108 (3):S18. doi: 10.1016/j.ijrobp.2020.07.2101

85. Jani A, Schreibmann E, Goyal S, Raghuveer H, Hershatter B, Rossi PJ, et al. Initial Report of a Randomized Trial Comparing Conventional- vs Conventional Plus Fluciclovine (18f) PET/CT Imaging-Guided PostProstatectomy Radiotherapy for Prostate Cancer. Int J Radiat Oncol Biol Phys (2020) 108(5):1397. doi: 10.2139/ssrn.3752666

86. Andriole GL, Kostakoglu L, Chau A, Duan F, Mahmood U, Mankoff DA, et al. The Impact of Positron Emission Tomography With 18F-Fluciclovine on the Treatment of Biochemical Recurrence of Prostate Cancer: Results From the LOCATE Trial. J Urol (2019) 201(2):322-31. doi: 10.1097/ 01.JU.0000556028.10817.8c

87. Scarsbrook AF, Bottomley D, Teoh EJ, Bradley KM, Payne H, Afaq A, et al. Effect of (18)F-Fluciclovine Positron Emission Tomography on the
Management of Patients With Recurrence of Prostate Cancer: Results From the FALCON Trial. Int J Radiat Oncol Biol Phys (2020) 107(2):31624. doi: 10.1016/j.ijrobp.2020.01.050

88. Sweeney CJ, Chen YH, Carducci M, Liu G, Jarrard DF, Eisenberger M, et al. Chemohormonal Therapy in Metastatic Hormone-Sensitive Prostate Cancer. N Engl J Med (2015) 373(8):737-46. doi: 10.1056/NEJMoa1503747

89. Deek MP, Van der Eecken K, Phillips R, Parikh NR, Isaacsson Velho P, Lotan TL, et al. The Mutational Landscape of Metastatic Castration-Sensitive Prostate Cancer: The Spectrum Theory Revisited. Eur Urol (2021) S03022838(20):31026-5. doi: 10.1016/j.eururo.2020.12.040

90. Boeve LMS, Hulshof M, Vis AN, Zwinderman AH, Twisk JWR, Witjes WPJ, et al. Effect on Survival of Androgen Deprivation Therapy Alone Compared to Androgen Deprivation Therapy Combined With Concurrent Radiation Therapy to the Prostate in Patients With Primary Bone Metastatic Prostate Cancer in a Prospective Randomised Clinical Trial: Data From the HORRAD Trial. Eur Urol (2019) 75(3):410-8. doi: 10.1016/ j.eururo.2018.11.008

91. Parker CC, James ND, Brawley CD, Clarke NW, Hoyle AP, Ali A, et al. Radiotherapy to the Primary Tumour for Newly Diagnosed, Metastatic Prostate Cancer (STAMPEDE): A Randomised Controlled Phase 3 Trial. Lancet (London England) (2018) 392(10162):2353-66. doi: 10.1016/S01406736(18)32486-3

92. Sun X, Briel M, Walter SD, Guyatt GH. Is a Subgroup Effect Believable? Updating Criteria to Evaluate the Credibility of Subgroup Analyses. BMJ (Clin Res Ed) (2010) 340:c117. doi: 10.1136/bmj.c117

93. Ali A, Hoyle A, Haran ÁM, Brawley CD, Cook A, Amos C, et al. Association of Bone Metastatic Burden With Survival Benefit From Prostate Radiotherapy in Patients With Newly Diagnosed Metastatic Prostate Cancer: A Secondary Analysis of a Randomized Clinical Trial. JAMA Oncol (2021) 7(4):555-63. doi: 10.1001/jamaoncol.2020.7857

94. Ost P, Reynders D, Decaestecker K, Fonteyne V, Lumen N, De Bruycker A, et al. Surveillance or Metastasis-Directed Therapy for Oligometastatic Prostate Cancer Recurrence: A Prospective, Randomized, Multicenter Phase Ii Trial. J Clin Oncol (2018) 36(5):446-53. doi: 10.1200/ JCO.2017.75.4853

95. Phillips R, Shi WY, Deek M, Radwan N, Lim SJ, Antonarakis ES, et al. Outcomes of Observation vs Stereotactic Ablative Radiation for Oligometastatic Prostate Cancer: The ORIOLE Phase 2 Randomized Clinical Trial. JAMA Oncol (2020) 6(5):650-9. doi: 10.1001/ jamaoncol.2020.0147

96. Miyamoto DT, Mouw KW, Feng FY, Shipley WU, Efstathiou JA. Molecular Biomarkers in Bladder Preservation Therapy for Muscle-Invasive Bladder Cancer. Lancet Oncol (2018) 19(12):e683-95. doi: 10.1016/S1470-2045(18) 30693-4

97. Pelucchi C, Bosetti C, Negri E, Malvezzi M, La Vecchia C. Mechanisms of Disease: The Epidemiology of Bladder Cancer. Nat Clin Pract Urol (2006) 3 (6):327-40. doi: 10.1038/ncpuro0510

98. Choudhury A, Nelson LD, Teo MT, Chilka S, Bhattarai S, Johnston CF, et al. MRE11 Expression is Predictive of Cause-Specific Survival Following Radical Radiotherapy for Muscle-Invasive Bladder Cancer. Cancer Res (2010) 70(18):7017-26. doi: 10.1158/0008-5472.CAN-10-1202

99. Magliocco AM, Moughan J, Simko J, Efstathiou JA, Gray PJ, Hagan MP, et al. The Impact of MRE11 in Nuclear to Cytoplasmic Ratio on Outcomes in Muscle Invasive Bladder Cancer an Analysis of NRG/RTOG 8802, 8903, 9506, 9706, 9906, and 0233. J Clin Oncol (2017) 35(6_suppl):343-. doi: 10.1200/JCO.2017.35.6_suppl.343

100. Laurberg JR, Brems-Eskildsen AS, Nordentoft I, Fristrup N, Schepeler T, Ulhøi BP, et al. Expression of TIP60 (Tat-Interactive Protein) and MRE11 (Meiotic Recombination 11 Homolog) Predict Treatment-Specific Outcome of Localised Invasive Bladder Cancer. BJU Int (2012) 110(11 Pt C):E1228-36. doi: 10.1111/j.1464-410X.2012.11564.x

101. Teo MTW, Dyrskjøt L, Nsengimana J, Buchwald C, Snowden H, Morgan J, et al. Next-Generation Sequencing Identifies Germline MRE11A Variants as Markers of Radiotherapy Outcomes in Muscle-Invasive Bladder Cancer. Ann Oncol Off J Eur Soc Med Oncol (2014) 25(4):877-83. doi: 10.1093/annonc/mdu014

102. Desai NB, Scott SN, Zabor EC, Cha EK, Hreiki J, Sfakianos JP, et al. Genomic Characterization of Response to Chemoradiation in Urothelial Bladder Cancer. Cancer (2016) 122(23):3715-23. doi: 10.1002/cncr.30219 
103. Chakravarti A, Winter K, Wu CL, Kaufman D, Hammond E, Parliament M, et al. Expression of the Epidermal Growth Factor Receptor and Her-2 are Predictors of Favorable Outcome and Reduced Complete Response Rates, Respectively, in Patients With Muscle-Invading Bladder Cancers Treated by Concurrent Radiation and Cisplatin-Based Chemotherapy: A Report From the Radiation Therapy Oncology Group. Int J Radiat Oncol Biol Phys (2005) 62(2):309-17. doi: 10.1016/j.ijrobp.2004.09.047

104. Inoue M, Koga F, Yoshida S, Tamura T, Fujii Y, Ito E, et al. Significance of ERBB2 Overexpression in Therapeutic Resistance and Cancer-Specific Survival in Muscle-Invasive Bladder Cancer Patients Treated With Chemoradiation-Based Selective Bladder-Sparing Approach. Int J Radiat Oncol Biol Phys (2014) 90(2):303-11. doi: 10.1016/j.ijrobp.2014.05.043

105. Michaelson MD, Hu C, Pham HT, Dahl DM, Lee-Wu C, Swanson GP, et al. A Phase 1/2 Trial of a Combination of Paclitaxel and Trastuzumab With Daily Irradiation or Paclitaxel Alone With Daily Irradiation After Transurethral Surgery for Noncystectomy Candidates With MuscleInvasive Bladder Cancer (Trial NRG Oncology RTOG 0524). Int J Radiat Oncol Biol Phys (2017) 97(5):995-1001. doi: 10.1016/j.ijrobp.2016.12.018

106. The Cancer Genome Atlas Research Network. Comprehensive Molecular Characterization of Urothelial Bladder Carcinoma. Nature (2014) 507 (7492):315-22. doi: 10.1038/nature12965

107. Choi W, Porten S, Kim S, Willis D, Plimack ER, Hoffman-Censits J, et al. Identification of Distinct Basal and Luminal Subtypes of Muscle-Invasive Bladder Cancer With Different Sensitivities to Frontline Chemotherapy. Cancer Cell (2014) 25(2):152-65. doi: 10.1016/j.ccr.2014.01.009

108. Damrauer JS, Hoadley KA, Chism DD, Fan C, Tiganelli CJ, Wobker SE, et al. Intrinsic Subtypes of High-Grade Bladder Cancer Reflect the Hallmarks of Breast Cancer Biology. Proc Natl Acad Sci USA (2014) 111(8):3110-5. doi: 10.1073/pnas.1318376111

109. Robertson AG, Kim J, Al-Ahmadie H, Bellmunt J, Guo G, Cherniack AD, et al. Comprehensive Molecular Characterization of Muscle-Invasive Bladder Cancer. Cell (2018) 174(4):1033. doi: 10.1016/j.cell.2018.07.036

110. Sjödahl G, Lauss M, Lövgren K, Chebil G, Gudjonsson S, Veerla S, et al. A Molecular Taxonomy for Urothelial Carcinoma. Clin Cancer Res An Off J Am Assoc Cancer Res (2012) 18(12):3377-86. doi: 10.1158/1078-0432.CCR-120077-T

111. Efstathiou JA, Mouw KW, Gibb EA, Liu Y, Wu CL, Drumm MR, et al. Impact of Immune and Stromal Infiltration on Outcomes Following Bladder-Sparing Trimodality Therapy for Muscle-Invasive Bladder Cancer. Eur Urol (2019) 76(1):59-68. doi: 10.1016/j.eururo.2019.01.011

112. Song YP, Mistry H, Choudhury A, Hoskin P. Long-Term Outcomes of Hypoxia Modification in Bladder Preservation: Update From BCON Trial. J Clin Oncol (2019) 37(7_suppl):356-. doi: 10.1200/JCO.2019.37.7_suppl.356

113. Yang L, Williamson A, Irlam J, Helen D, Hoskin P, West CML, et al. Molecular Subtyping of Muscle-Invasive Bladder Cancer Predicts Benefit of Hypoxia-Targeting Therapy. Int J Radiat Oncol Biol Phys (2017) 99(2):E222. doi: 10.1016/j.ijrobp.2017.06.1134

114. Yang L, Taylor J, Eustace A, Irlam JJ, Denley H, Hoskin PJ, et al. A Gene Signature for Selecting Benefit From Hypoxia Modification of Radiotherapy for High-Risk Bladder Cancer Patients. Clin Cancer Res An Off J Am Assoc Cancer Res (2017) 23(16):4761-8. doi: 10.1158/1078-0432.CCR-17-0038

115. Christensen E, Birkenkamp-Demtröder K, Sethi H, Shchegrova S, Salari R, Nordentoft I, et al. Early Detection of Metastatic Relapse and Monitoring of Therapeutic Efficacy by Ultra-Deep Sequencing of Plasma Cell-Free DNA in Patients With Urothelial Bladder Carcinoma. J Clin Oncol (2019) 37 (18):1547-57. doi: 10.1158/1538-7445.AM2019-913

116. Zhang Z, Fan W, Deng Q, Tang S, Wang P, Xu P, et al. The Prognostic and Diagnostic Value of Circulating Tumor Cells in Bladder Cancer and Upper Tract Urothelial Carcinoma: A Meta-Analysis of 30 Published Studies. Oncotarget (2017) 8(35):59527-38. doi: 10.18632/oncotarget.18521

117. Choudhury A, Porta N, Hall E, Song YP, Owen R, MacKay R, et al. Hypofractionated Radiotherapy in Locally Advanced Bladder Cancer: An Individual Patient Data Meta-Analysis of the BC2001 and. Lancet Oncol (2021) 22(2):246-55. doi: 10.1016/S1470-2045(20)30607-0

118. Marcq G, Souhami L, Cury FL, Salimi A, Aprikian A, Tanguay S, et al. Phase I Trial of Atezolizumab Plus Trimodal Therapy in Patients With Localized Muscle-Invasive Bladder Cancer. Int J Radiat Oncol Biol Phys (2021) S03603016(20):34729-5. doi: 10.1016/j.ijrobp.2020.12.033
119. Tree AC, Jones K, Hafeez S, Sharabiani MTA, Harrington KJ, Lalondrelle S, et al. Dose-Limiting Urinary Toxicity With Pembrolizumab Combined With Weekly Hypofractionated Radiation Therapy in Bladder Cancer. Int J Radiat Oncol Biol Phys (2018) 101(5):1168-71. doi: 10.1016/j.ijrobp.2018.04.070

120. Apolo AB, Riches J, Schöder H, Akin O, Trout A, Milowsky MI, et al. Clinical Value of fluorine-18 2-Fluoro-2-deoxy-D-glucose Positron Emission Tomography/Computed Tomography in Bladder Cancer. J Clin Oncol (2010) 28(25):3973-8. doi: 10.1200/JCO.2010.28.7052

121. Kibel AS, Dehdashti F, Katz MD, Klim AP, Grubb RL, Humphrey PA, et al. Prospective Study of [18F]Fluorodeoxyglucose Positron Emission Tomography/Computed Tomography for Staging of Muscle-Invasive Bladder Carcinoma. J Clin Oncol (2009) 27(26):4314-20. doi: 10.1200/ JCO.2008.20.6722

122. Wang H, Luo C, Zhang F, Guan J, Li S, Yao H, et al. Multiparametric MRI for Bladder Cancer: Validation of VI-RADS for the Detection of Detrusor Muscle Invasion. Radiology (2019) 291(3):668-74. doi: 10.1148/ radiol.2019182506

123. Yoshida S, Koga F, Kawakami S, Ishii C, Tanaka H, Numao N, et al. Initial Experience of Diffusion-Weighted Magnetic Resonance Imaging to Assess Therapeutic Response to Induction Chemoradiotherapy Against MuscleInvasive Bladder Cancer. Urology (2010) 75(2):387-91. doi: 10.1016/ j.urology.2009.06.111

124. Yoshida S, Koga F, Kobayashi S, Ishii C, Tanaka H, Tanaka H, et al. Role of Diffusion-Weighted Magnetic Resonance Imaging in Predicting Sensitivity to Chemoradiotherapy in Muscle-Invasive Bladder Cancer. Int J Radiat Oncol Biol Phys (2012) 83(1):e21-7. doi: 10.1016/j.ijrobp.2011.11.065

125. Yoshida S, Takahara T, Kwee TC, Waseda Y, Kobayashi S, Fujii Y. DWI as an Imaging Biomarker for Bladder Cancer. AJR Am J Roentgenol (2017) 208 (6):1218-28. doi: 10.2214/AJR.17.17798

126. Network NCC. Testicular Cancer (2021). Available at: https://www.nccn.org/ professionals/physician_gls/pdf/testicular.pdf.

127. Krege $S$, Albers $P$, Heidenreich A. The Role of Tumour Markers in Diagnosis and Management of Testicular Germ Cell Tumours. Der Urol Ausg A (2011) 50(3):313-21. doi: 10.1007/s00120-010-2414-5

128. Vesprini D, Chung P, Tolan S, Gospodarowicz M, Jewett M, O’Malley M, et al. Utility of Serum Tumor Markers During Surveillance for Stage I Seminoma. Cancer (2012) 118(21):5245-50. doi: 10.1002/cncr.27539

129. Chung P, Daugaard G, Tyldesley S, Atenafu EG, Panzarella T, Kollmannsberger C, et al. Evaluation of a Prognostic Model for Risk of Relapse in Stage I Seminoma Surveillance. Cancer Med (2015) 4(1):155-60. doi: $10.1002 / \mathrm{cam} 4.324$

130. Warde P, Specht L, Horwich A, Oliver T, Panzarella T, Gospodarowicz M, et al. Prognostic Factors for Relapse in Stage I Seminoma Managed by Surveillance: A Pooled Analysis. J Clin Oncol (2002) 20(22):4448-52. doi: 10.1200/JCO.2002.01.038

131. De Martino M, Chieffi P, Esposito F. miRNAs and Biomarkers in Testicular Germ Cell Tumors: An Update. Int J Mol Sci (2021) 22(3):1380. doi: 10.3390/ ijms 22031380

132. Lakpour N, Saliminejad K, Ghods R, Reza Sadeghi M, Pilatz A, Khosravi F, et al. Potential Biomarkers for Testicular Germ Cell Tumour: Risk Assessment, Diagnostic, Prognostic and Monitoring of Recurrence. Andrologia (2021) 53(4):e13998. doi: 10.1111/and.13998

133. JK Joffe, FH Cafferty, L Murphy, GJS Rustin, S Sohaib, S Swift, et al eds. Imaging Modality and Frequency in Surveillance of Stage I Seminoma Testicular Cancer: Results From a Randomized, Phase III, Factorial Trial (TRISST). In: Genitourinary Cancers Symposium. American Society of Clinical Oncology.

134. Jones WG, Fossa SD, Mead GM, Roberts JT, Sokal M, Horwich A, et al. Randomized Trial of 30 Versus 20 Gy in the Adjuvant Treatment of Stage I Testicular Seminoma: A Report on Medical Research Council Trial TE18, European Organisation for the Research and Treatment of Cancer Trial 30942 (Isrctn18525328). J Clin Oncol (2005) 23(6):1200-8. doi: 10.1200/JCO.2005.08.003

135. Pasalic D, Prajapati S, Ludmir EB, Tang C, Choi S, Kudchadker R, et al. Outcomes and Toxicities of Proton and Photon Radiation Therapy for Testicular Seminoma. Int J Particle Ther (2020) 7(2):11-20. doi: 10.14338/ IJPT-20-00018.1

136. Efstathiou JA, Paly JJ, Lu HM, Athar BS, Moteabbed M, Niemierko A, et al. Adjuvant Radiation Therapy for Early Stage Seminoma: Proton Versus 
Photon Planning Comparison and Modeling of Second Cancer Risk. Radiother Oncol J Eur Soc Ther Radiol Oncol (2012) 103(1):12-7. doi: 10.1016/j.radonc.2012.01.012

137. Fosså SD, Horwich A, Russell JM, Roberts JT, Cullen MH, Hodson NJ, et al. Optimal Planning Target Volume for Stage I Testicular Seminoma: A Medical Research Council Randomized Trial. Medical Research Council Testicular Tumor Working Group. J Clin Oncol (1999) 17(4):1146. doi: 10.1200/JCO.1999.17.4.1146

138. Paly JJ, Efstathiou JA, Hedgire SS, Chung PW, O’Malley M, Shah A, et al. Mapping Patterns of Nodal Metastases in Seminoma: Rethinking Radiotherapy Fields. Radiother Oncol J Eur Soc Ther Radiol Oncol (2013) 106(1):64-8. doi: 10.1016/j.radonc.2012.12.002

139. Caputo PA, Zargar H, Ramirez D, Andrade HS, Akca O, Gao T, et al. Cryoablation Versus Partial Nephrectomy for Clinical T1b Renal Tumors: A Matched Group Comparative Analysis. Eur Urol (2017) 71(1):111-7. doi: 10.1016/j.eururo.2016.08.039

140. Psutka SP, Feldman AS, McDougal WS, McGovern FJ, Mueller P, Gervais DA. Long-Term Oncologic Outcomes After Radiofrequency Ablation for T1 Renal Cell Carcinoma. Eur Urol (2013) 63(3):486-92. doi: 10.1016/j.eururo.2012.08.062

141. Straka C, Kim DW, Timmerman RD, Pedrosa I, Jacobs C, Brugarolas J. Ablation of a Site of Progression With Stereotactic Body Radiation Therapy Extends Sunitinib Treatment From 14 to 22 Months. J Clin Oncol (2013) 31 (23):e401-3. doi: 10.1200/JCO.2012.47.7455

142. Correa RJM, Louie AV, Zaorsky NG, Lehrer EJ, Ellis R, Ponsky L, et al. The Emerging Role of Stereotactic Ablative Radiotherapy for Primary Renal Cell Carcinoma: A Systematic Review and Meta-Analysis. Eur Urol Focus (2019) 5(6):958-69. doi: 10.1016/j.euf.2019.06.002

143. Siva S, Jackson P, Kron T, Bressel M, Lau E, Hofman M, et al. Impact of Stereotactic Radiotherapy on Kidney Function in Primary Renal Cell Carcinoma: Establishing a Dose-Response Relationship. Radiother Oncol J Eur Soc Ther Radiol Oncol (2016) 118(3):540-6. doi: 10.1016/j.radonc.2016.01.027
144. Xie G, Gu D, Zhang L, Chen S, Wu D. A Rapid and Systemic Complete Response to Stereotactic Body Radiation Therapy and Pembrolizumab in a Patient With Metastatic Renal Cell Carcinoma. Cancer Biol Ther (2017) 18 (8):547-51. doi: 10.1080/15384047.2017.1345389

145. Motzer RJ, Escudier B, McDermott DF, George S, Hammers HJ, Srinivas S, et al. Nivolumab Versus Everolimus in Advanced Renal-Cell Carcinoma. N Engl J Med (2015) 373(19):1803-13. doi: 10.1056/ NEJMoa 1510665

146. Motzer RJ, Tannir NM, McDermott DF, Arén Frontera O, Melichar B, Choueiri TK, et al. Nivolumab Plus Ipilimumab Versus Sunitinib in Advanced Renal-Cell Carcinoma. N Engl J Med (2018) 378(14):1277-90. doi: 10.1056/NEJMoa1712126

147. S Siva, M Bressel, S Wood, M Shaw, S Loi, S Sandhu, et al. eds. Stereotactic Radiotherapy and Pembrolizumab for Oligometastatic Renal Tumors: The RAPPORT Trial. In: Genitourinary Cancers Symposium. American Society of Clinical Oncology.

Conflict of Interest: JAE has served as consultant to: Blue Earth Diagnostics, Boston Scientific, AstraZeneca; and on advisory boards for Myovant Sciences, Roivant Pharma, Merck and Progenics.

The remaining author declares that the research was conducted in the absence of any commercial or financial relationships that could be construed as a potential conflict of interest.

Copyright $\odot 2021$ Kamran and Efstathiou. This is an open-access article distributed under the terms of the Creative Commons Attribution License (CC BY). The use, distribution or reproduction in other forums is permitted, provided the original author(s) and the copyright owner(s) are credited and that the original publication in this journal is cited, in accordance with accepted academic practice. No use, distribution or reproduction is permitted which does not comply with these terms. 